\title{
Surface Circulation at the Tip of the Antarctic Peninsula from Drifters
}

\author{
ANDREW F. THOMPSON AND KAREN J. HEYWOOD \\ School of Environmental Sciences, University of East Anglia, Norwich, United Kingdom \\ SALLY E. THORPE \\ British Antarctic Survey, Natural Environment Research Council, Cambridge, United Kingdom
}

ANGELIKA H. H. RENNER

British Antarctic Survey, Natural Environment Research Council, Cambridge, and School of Environmental Sciences, University of East Anglia, Norwich, United Kingdom

ARMANDO TRASVIÑA

Centro de Investigación Científica y de Educación Superior de Ensenada, Departamento de Oceanografia Fisica, Unidad La Paz, La Paz, Mexico

(Manuscript received 6 February 2008, in final form 3 June 2008)

\begin{abstract}
An array of 40 surface drifters, drogued at 15-m depth, was deployed in February 2007 to the east of the tip of the Antarctic Peninsula as part of the Antarctic Drifter Experiment: Links to Isobaths and Ecosystems (ADELIE) project. Data obtained from these drifters and from a select number of local historical drifters provide the most detailed observations to date of the surface circulation in the northwestern Weddell Sea. The Antarctic Slope Front (ASF), characterized by a $\sim 20 \mathrm{~cm} \mathrm{~s}^{-1}$ current following the $1000-\mathrm{m}$ isobath, is the dominant feature east of the peninsula. The slope front bifurcates when it encounters the South Scotia Ridge with the drifters following one of three paths. Drifters (i) are carried westward into Bransfield Strait; (ii) follow the 1000-m isobath to the east along the southern edge of the South Scotia Ridge; or (iii) become entrained in a large-standing eddy over the South Scotia Ridge. Drifters are strongly steered by contours of $f / h$ (Coriolis frequency/depth) as shown by calculations of the first two moments of displacement in both geographic coordinates and coordinates locally aligned with contours of $f / h$. An eddy-mean decomposition of the drifter velocities indicates that shear in the mean flow makes the dominant contribution to dispersion in the along-f/h direction, but eddy processes are more important in dispersing particles across contours of $f / h$. The results of the ADELIE study suggest that the circulation near the tip of the Antarctic Peninsula may influence ecosystem dynamics in the Southern Ocean through Antarctic krill transport and the export of nutrients.
\end{abstract}

\section{Introduction}

The circulation near the tip of the Antarctic Peninsula is crucial for enabling the export of unique water properties found along the rim of the Weddell Gyre into the Antarctic Circumpolar Current (ACC). Ant-

Corresponding author address: Andrew F. Thompson, Department of Applied Mathematics and Theoretical Physics, University of Cambridge, Wilberforce Road, Cambridge CB3 0WA, United Kingdom.

E-mail: a.f.thompson@damtp.cam.ac.uk arctic Bottom Water formed over the continental shelf in the southern Weddell Sea passes through gaps in the complex topography near the tip of the Antarctic Peninsula before entering the ACC (Orsi et al. 1999). Once in the ACC, this dense water spreads throughout the World Ocean. Considering water masses close to the surface, Antarctic waters overlying continental shelves typically have iron concentrations that are an order of magnitude larger than pelagic Antarctic waters, including pelagic waters of the Scotia Sea (Martin et al. 1990; Fitzwater et al. 2000). It is now generally accepted that iron limits phytoplankton biomass in pelagic Antarctic 
waters, and there is increasing evidence that this is also true in coastal waters (Fitzwater et al. 2000; discussion in Holm-Hansen et al. 2004a). The export of iron-rich waters found near the Antarctic Peninsula may explain elevated chlorophyll levels_-visible from satellite observations-that extend from this region to South Georgia Island (Falkowski et al. 1998; Atkinson et al. 2001; Korb et al. 2004). Therefore, the pathways through which exchange occurs between the Weddell Sea and the ACC influence both the global overturning circulation and local biological dynamics.

The margins of Antarctica are dominated by two topographically constrained westward currents, the Antarctic Slope Front (ASF) and the Antarctic Coastal Current (CC). The Antarctic Slope Front marks the subsurface boundary between cold, relatively freshwater found on the Antarctic continental shelf and warmer, more saline water found farther offshore (Jacobs 1986, 1991). The ASF is consistently found above or just offshore of the shelf break.

In the western Weddell Sea the speed of the ASF is uniform throughout most of the water column, but it peaks around $20 \mathrm{~cm} \mathrm{~s}^{-1}$ near the seabed due to the outflow of dense bottom water (Muench and Gordon 1995; Fahrbach et al. 2001; Thompson and Heywood 2008; hereafter TH08). It has been suggested that the position of the ASF is in part determined by this deep outflow (Gill 1973; Baines 2008, manuscript submitted to Deep-Sea Res. II). The CC is found broadly over the continental shelf and is not tied to a specific topographical feature. In regions where the continental shelf narrows, the CC may merge with the ASF (Heywood et al. 1998).

Within the Weddell Gyre, the ASF and CC act to precondition shelf waters for the formation of Antarctic Bottom Water (Fahrbach et al. 1992), melt the underside of ice shelves (Fahrbach et al. 1994), and transport Antarctic krill and nutrients (Pauly et al. 2000). Near the tip of the Antarctic Peninsula, though, the ASF and $\mathrm{CC}$ encounter complex topography and come into confluence with the ACC in the region over and surrounding the South Scotia Ridge known as the Weddell Scotia Confluence (Patterson and Sievers 1980). Interactions with topography and the ACC significantly modify the properties and behavior of the ASF and CC and have contributed to difficulties in detecting and tracking these currents in this region. For example, Whitworth et al. (1998) have shown that the traditional markers of the currents-for example, identifying the ASF with the shoreward extension of the $0^{\circ} \mathrm{C}$ isotherm (Jacobs 1991) - are no longer applicable in the northwestern Weddell Sea. Furthermore, most large-scale maps of the mean circulation in the Weddell Gyre, such as those constructed by Orsi et al. (1993) from historical hydrographic data, have proven too coarse to resolve the fates of the ASF and CC near the tip of the Antarctic Peninsula.

Heywood et al. (2004) used hydrographic data located over and around the South Scotia Ridge to infer the paths of the ASF and CC. A distinct CC was detected east of Joinville Island that flowed westward into the southern portion of Bransfield Strait, where it could no longer be tracked. The ASF was associated with cyclonic flow around Powell Basin between the 1000and 2000-m isobaths. Heywood et al. (2004) suggested that the ASF splits in two over the South Scotia Ridge, with one part following a complicated, topographically steered route out through the Weddell Scotia Confluence into the ACC, and the second part forming the Weddell Front above the 3000-m isobath along the southern ridge of the South Orkney Plateau (see their Fig. 6). We note that in Heywood et al. (2004), identification of the ASF over the South Scotia Ridge was made difficult by the predominantly along-isobath alignment of the hydrographic stations.

Thus the goal of the Antarctic Drifter Experiment: Links to Isobaths and Ecosystems (ADELIE) project was to provide a more complete description of the ASF and the CC near the tip of the Antarctic Peninsula and, specifically, to identify where and to what extent crossslope transport enables export of water masses formed on the shelf into deeper waters. Multiple transects across the continental shelf and slope to the east of the peninsula's tip (Fig. 1) were completed to obtain hydrographic data and to deploy 40 surface drifters. The surface drifters represent the first dedicated experiment using Lagrangian instruments to the east of the Antarctic Peninsula and will be the focus of this study. ${ }^{1}$ This study highlights the role of topography in steering currents in this region and gives an indication of possible pathways for nutrient and Antarctic krill transport near the Antarctic Peninsula.

The dataset used in this study is described in section 2. An overview of the surface circulation at the tip of the Antarctic Peninsula is provided in section 3. Section 4 gives a statistical description of the data and focuses on the dispersion of the drifters relative to contours of Coriolis frequency/depth $(f / h)$ to determine the extent of

\footnotetext{
${ }^{1}$ Iceberg drift has previously been used to document surface currents in the Weddell Sea (e.g., Wadhams et al. 1989; Schodlok et al. 2006). The deviation of iceberg drift from a true passive tracer is expected to be greater than that of a drifter because of the large above-surface extent of the iceberg that is susceptible to wind forcing.
} 

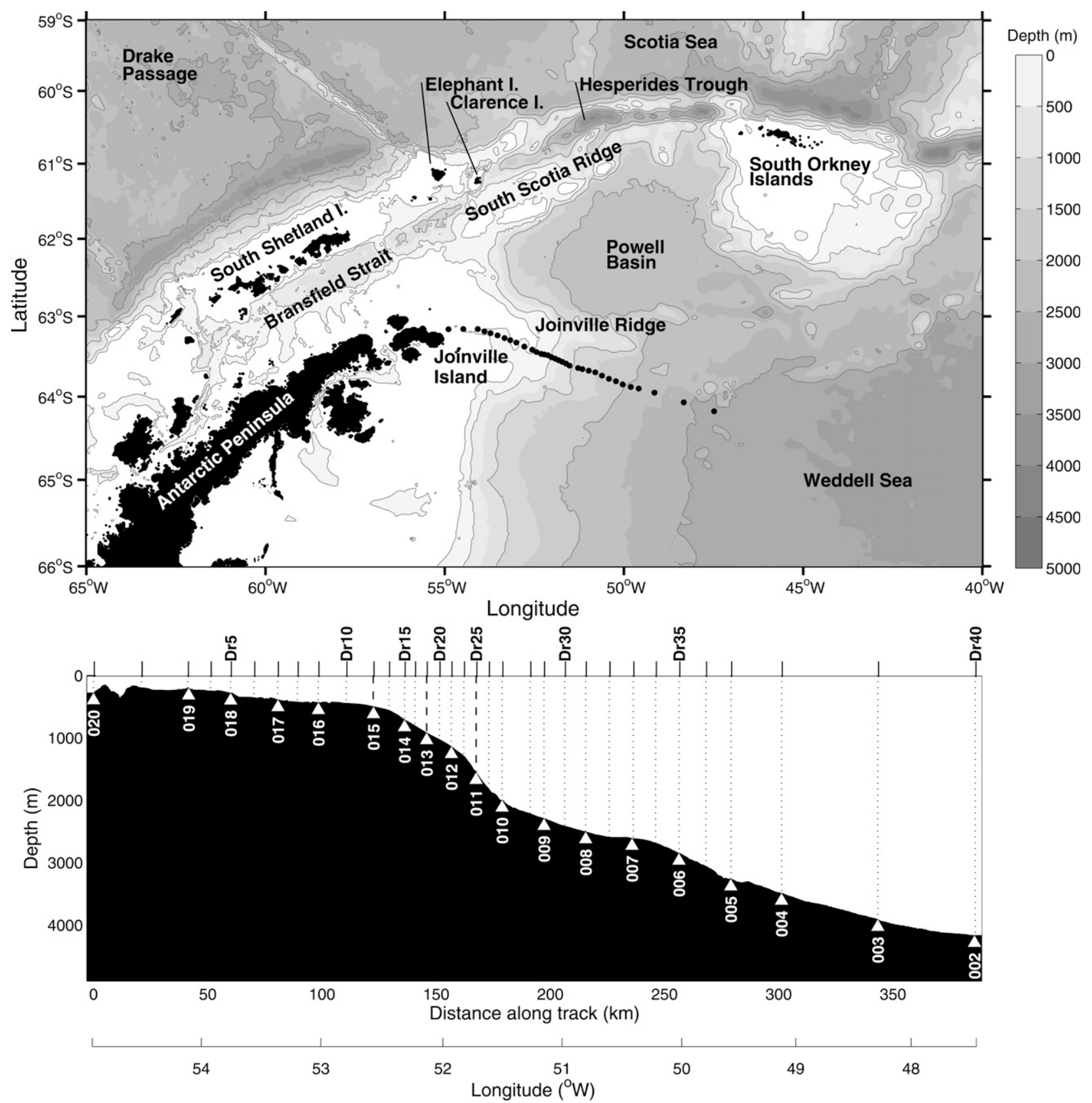

FIG. 1. (top) Bathymetry of the ADELIE study region. The contours indicate the 500-, 1000-, 2000-, 3000-, and 4000-m isobaths; land is shaded black. The black dots indicate the deployment locations of the 40 surface drifters released between 8 and 10 Feb 2007 . Important geographical features are labeled. (bottom) Cross section of the ADELIE drifter-deployment transect; the black shaded region shows the topography of the continental shelf and slope. The dotted lines indicate the drifter deployment locations, while the dashed lines indicate three stations where three drifters were deployed simultaneously. The white triangles indicate hydrographic stations carried out on a return transect.

topographical steering. A discussion of the results and a summary of the conclusions are provided in section 5 .

\section{Data}

Forty Clearsat II surface drifters were released from the RRS James Clark Ross (JCR) in February 2007 along a transect starting near Joinville Island and crossing the continental shelf and continental slope (Fig. 1). The drifters were deployed approximately every $10 \mathrm{~km}$ along the transect, with the finest spatial resolution over the shelf-slope transition (Fig. 1). Three groups of three drifters were also released at the 550-, 950-, and 
TABLE 1. Deployment and lifetime information for the surface drifters deployed during ADELIE (as of 31 Dec 2007). Drifters 7054270561 were equipped with GPS navigation, while drifters 71212-71231 (SVP) were tracked solely with the Argos satellite system. In some cases, the drifters did not start recording immediately after deployment, thus the data start date, given in Julian day (jday), is often later than the deployment date. In many cases the drogue was lost before the drifter stopped responding; the data record is taken to end when the drogue is lost. The death types are 1: still responding without drogue; 2 : stopped responding; 3 : lost drogue and stopped responding at a later date. For drifter 70560, GPS fixes failed part way through its trajectory; the remainder of the path is determined from the Argos fixes.

\begin{tabular}{|c|c|c|c|c|c|c|c|c|c|c|}
\hline \multirow[b]{2}{*}{ Id No. } & \multirow[b]{2}{*}{ Date } & \multicolumn{3}{|c|}{ Deployment } & \multirow{2}{*}{$\begin{array}{l}\text { Data start } \\
\text { (jday) }\end{array}$} & \multirow{2}{*}{$\begin{array}{l}\text { Lost drogue } \\
\text { (jday) }\end{array}$} & \multirow{2}{*}{$\begin{array}{l}\text { Data end } \\
\text { (jday) }\end{array}$} & \multirow{2}{*}{$\begin{array}{c}\text { No. of } \\
\text { days }\end{array}$} & \multirow{2}{*}{$\begin{array}{l}\text { Drifter } \\
\text { type }\end{array}$} & \multirow{2}{*}{$\begin{array}{c}\text { Death } \\
\text { code }\end{array}$} \\
\hline & & Time (UTC) & Lat $\left({ }^{\circ} \mathrm{S}\right)$ & Lon $\left({ }^{\circ} \mathrm{W}\right)$ & & & & & & \\
\hline 70546 & 8 Feb 2007 & 1849 & 63.16 & 54.90 & 40.88 & 185.63 & - & 145 & GPS & 1 \\
\hline 70549 & 8 Feb 2007 & 2012 & 63.16 & 54.48 & 41.58 & - & 75.29 & 34 & GPS & 2 \\
\hline 70552 & 8 Feb 2007 & 2135 & 63.16 & 54.07 & 41.50 & 184.29 & 191.96 & 143 & GPS & 3 \\
\hline 71215 & 8 Feb 2007 & 2222 & 63.19 & 53.89 & 39.96 & - & 73.17 & 33 & SVP & 2 \\
\hline 70550 & 8 Feb 2007 & 2257 & 63.21 & 53.27 & 41.50 & 117.67 & - & 76 & GPS & 1 \\
\hline 71217 & 8 Feb 2007 & 2347 & 63.24 & 53.52 & 40.04 & 49.96 & - & 10 & SVP & 1 \\
\hline 70553 & 9 Feb 2007 & 0248 & 63.27 & 53.33 & 42.00 & 286.35 & - & 244 & GPS & 1 \\
\hline 71231 & 9 Feb 2007 & 1425 & 63.30 & 53.17 & 40.67 & 66.54 & 67.71 & 26 & SVP & 3 \\
\hline 70559 & 9 Feb 2007 & 1605 & 63.33 & 53.00 & 41.21 & 103.29 & 141.88 & 62 & GPS & 3 \\
\hline 71226 & 9 Feb 2007 & 1649 & 63.38 & 52.28 & 40.75 & 73.88 & 80.21 & 33 & SVP & 3 \\
\hline 70543 & 9 Feb 2007 & 1733 & 63.42 & 52.56 & 42.67 & 65.92 & 67.50 & 23 & GPS & 3 \\
\hline 70555 & 9 Feb 2007 & 1733 & 63.42 & 52.56 & 42.96 & - & 122.92 & 80 & GPS & 2 \\
\hline 70545 & 9 Feb 2007 & 1733 & 63.42 & 52.56 & 44.46 & - & 63.30 & 19 & GPS & 2 \\
\hline 71230 & 9 Feb 2007 & 1759 & 63.45 & 52.44 & 40.79 & - & 73.25 & 32 & SVP & 2 \\
\hline 70544 & 9 Feb 2007 & 1816 & 63.47 & 52.31 & 42.00 & 73.96 & 75.46 & 32 & GPS & 3 \\
\hline 71213 & 9 Feb 2007 & 1847 & 63.48 & 52.22 & 40.79 & - & 104.63 & 64 & SVP & 2 \\
\hline 70542 & 9 Feb 2007 & 1910 & 63.49 & 52.12 & 47.96 & 182.04 & - & 134 & GPS & 1 \\
\hline 70554 & 9 Feb 2007 & 1910 & 63.49 & 52.12 & 42.00 & - & 73.42 & 31 & GPS & 2 \\
\hline 70557 & 9 Feb 2007 & 1910 & 63.49 & 52.12 & 42.67 & - & 92.63 & 50 & GPS & 2 \\
\hline 71212 & 9 Feb 2007 & 1939 & 63.51 & 52.02 & 40.88 & 115.21 & 197.79 & 74 & SVP & 3 \\
\hline 70556 & 9 Feb 2007 & 1955 & 63.53 & 51.92 & 42.46 & 65.83 & 67.50 & 23 & GPS & 3 \\
\hline 71229 & 9 Feb 2007 & 2017 & 63.55 & 51.82 & 40.88 & 69.25 & 69.96 & 28 & SVP & 3 \\
\hline 70547 & 9 Feb 2007 & 2042 & 63.57 & 51.72 & 43.95 & 54.04 & 64.50 & 10 & GPS & 3 \\
\hline 70548 & 9 Feb 2007 & 2042 & 63.57 & 51.72 & 42.00 & 73.54 & 77.50 & 32 & GPS & 3 \\
\hline 70558 & 9 Feb 2007 & 2042 & 63.57 & 51.72 & 40.88 & 87.04 & 87.96 & 46 & GPS & 3 \\
\hline 71225 & 9 Feb 2007 & 2103 & 63.59 & 51.62 & 40.92 & - & 103.67 & 63 & SVP & 2 \\
\hline 70551 & 9 Feb 2007 & 2126 & 63.62 & 51.52 & 41.50 & 49.54 & - & 8 & GPS & 1 \\
\hline 71216 & 9 Feb 2007 & 2158 & 63.64 & 51.34 & 40.96 & 64.79 & - & 24 & SVP & 1 \\
\hline 71227 & 9 Feb 2007 & 2228 & 63.66 & 51.17 & 40.96 & 119.67 & 121.46 & 79 & SVP & 3 \\
\hline 71222 & 9 Feb 2007 & 2258 & 63.68 & 50.98 & 41.00 & - & 67.21 & 26 & SVP & 2 \\
\hline 70561 & 9 Feb 2007 & 2328 & 63.70 & 50.80 & 45.46 & - & 154.92 & 109 & GPS & 2 \\
\hline 71214 & 10 Feb 2007 & 0001 & 63.74 & 50.61 & 41.00 & - & 41.17 & 0 & SVP & 2 \\
\hline 71224 & 10 Feb 2007 & 0045 & 63.78 & 50.42 & 41.08 & 73.04 & - & 32 & SVP & 1 \\
\hline 71223 & 10 Feb 2007 & 0123 & 63.81 & 50.23 & 41.08 & - & 68.88 & 28 & SVP & 2 \\
\hline 70560 & 10 Feb 2007 & 0204 & 63.85 & 50.04 & 41.13 & 118.46 & - & 77 & GPS/SVP & 1 \\
\hline 71219 & 10 Feb 2007 & 0249 & 63.88 & 49.81 & 41.17 & - & 74.29 & 33 & SVP & 2 \\
\hline 71220 & 10 Feb 2007 & 0329 & 63.90 & 49.59 & 41.17 & 119.83 & - & 79 & SVP & 1 \\
\hline 71221 & 10 Feb 2007 & 0452 & 63.95 & 49.15 & 41.21 & 119.54 & 155.88 & 78 & SVP & 3 \\
\hline 71218 & 10 Feb 2007 & 0715 & 64.07 & 48.33 & 41.38 & 119.04 & 122.13 & 78 & SVP & 3 \\
\hline 71228 & 10 Feb 2007 & 0914 & 64.18 & 47.49 & 41.46 & 92.63 & 98.67 & 51 & SVP & 3 \\
\hline
\end{tabular}

1600-m isobaths (Fig. 1). Because of sea ice, the average life span of the drifter was about 58 days. $^{2}$ Only a single drifter failed immediately, and four drifters, three of which escaped into the ACC, lasted at least 4 months.

\footnotetext{
${ }^{2}$ The research cruise was postponed 2 weeks for logistical reasons, which increased the probability that sea ice would overtake the drifters.
}

Table 1 gives a summary of all the drifters including the deployment date and location, length of record, and cause of "death."

All drifters were drogued at 15-m depth following World Ocean Circulation Experiment (WOCE) standards for surface drifters. Twenty of the drifters were equipped with global positioning (GPS) devices while the remainder were tracked with the Argos satellite 


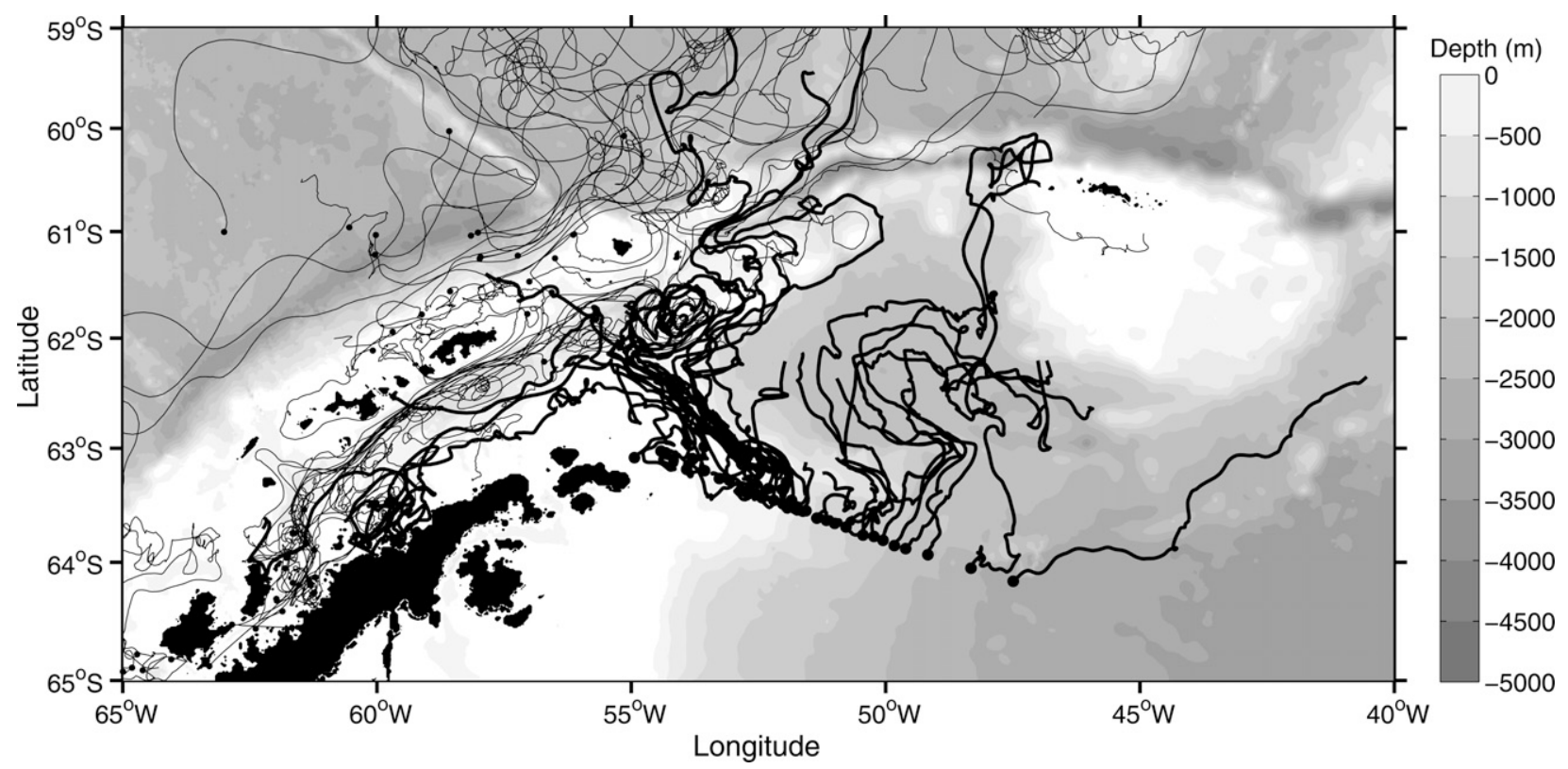

FIG. 2. Filtered trajectories of the 39 ADELIE drifters (one drifter failed immediately after deployment) are given by the bold curves. The thin curves represent historical drifters in the region, which have been used to determine the mean circulation. Deployment locations are marked by dots. Shading represents the bottom topography.

system. The GPS drifters provided a position fix roughly once every half-hour, with an accuracy as small as $25 \mathrm{~m}$. At these polar latitudes, a position fix from the Argos satellite system is available at least once an hour, but the accuracy of the fixes, as small as $150 \mathrm{~m}$ with an average of $350 \mathrm{~m}$, is considerably coarser than the GPS. The onset of sea ice formation in the western Weddell Sea coupled with drifting icebergs led to a more frequent loss of drogues than in traditional drifter studies. Velocities were only calculated while the drogue remained attached to the drifter. Velocities reported here are calculated from low-pass-filtered trajectories with a 38-h cutoff to remove tidal and inertial oscillations. These filtered trajectories are shown in Fig. 2. Velocities are determined from 6-hourly subsampled records following the method described by Hansen and Poulain (1996). The expected drogue slip relative to the water is less than $2 \mathrm{~cm} \mathrm{~s}^{-1}$ for winds up to $20 \mathrm{~m} \mathrm{~s}^{-1}$ (Niiler et al. 1995). The data from the ADELIE surface drifters are available through the Global Drifter Program Web site (www.aoml.noaa.gov/ phod/dac/gdp.html).

The ADELIE data complement the historical drifter data available through the Global Drifter Program. Historical drifters in the region have principally been released in Bransfield Strait as shown in Fig. 2. In this study we consider 55 historical drifters that pass close to the Antarctic Peninsula to help construct the mean circulation. The historical drifters span a period between
1989 and 2005 and are all drogued at 15-m depth. Table 2 gives a summary of the historical drifters used in this study.

In the following section, we also show data obtained from a $75-\mathrm{kHz}$ RD Instruments Ocean Surveyor (OS75) shipboard acoustic Doppler current profiler (SADCP) installed on the $J C R$. The SADCP was used to acquire current measurements up to a depth of $700 \mathrm{~m}$ throughout the cruise. ${ }^{3}$ SADCP measurements were recorded in 16-m bins and then averaged over a period of $10 \mathrm{~min}$; the error in the SADCP suggested by the manufacturer is $\pm 0.5 \mathrm{~cm} \mathrm{~s}^{-1}$. Sea surface temperature and sea surface salinity were recorded throughout the cruise on the JCR's oceanlogger that sampled seawater through an intake at 6-m depth. Further details on instrumentation and deployment can be found in the cruise report (Thompson 2007).

\section{The surface circulation of the northwestern Weddell Sea}

From a qualitative analysis of the ADELIE drifter trajectories combined with historical drifter trajectories

\footnotetext{
${ }^{3}$ The SADCP measurements shown are from the return hydrographic section. SADCP measurements collected during the drifter deployment section were contaminated by bubbles due to a large storm on 9 Feb. The hydrographic section was completed within 3 days of deployment.
} 
TABLE 2. Deployment and lifetime information for the historical drifters used in this study. The end date is taken to be the loss of the drogue if this precedes the end of transmission. All drifters are drogued at 15-m depth and are of type SVP tracked by the Argos satellite system. Further information on these drifters can be obtained from the Web site of the Global Drifter Program.

\begin{tabular}{|c|c|c|c|c|c|c|c|c|c|}
\hline \multirow[b]{2}{*}{ Id No. } & \multirow[b]{2}{*}{ Date } & \multicolumn{2}{|c|}{ Deployment } & \multirow[b]{2}{*}{ Data end } & \multirow[b]{2}{*}{ Id No. } & \multirow[b]{2}{*}{ Date } & \multicolumn{2}{|c|}{ Deployment } & \multirow[b]{2}{*}{ Data end } \\
\hline & & Lat $\left({ }^{\circ} \mathrm{S}\right)$ & Lon $\left({ }^{\circ} \mathrm{W}\right)$ & & & & Lat $\left({ }^{\circ} \mathrm{S}\right)$ & Lon $\left({ }^{\circ} \mathrm{W}\right)$ & \\
\hline 8911512 & 1 Nov 1989 & 64.08 & 61.36 & 4 Aug 1990 & 24477 & 13 Feb 2002 & 66.66 & 69.47 & 20 Jun 2002 \\
\hline 8911524 & 1 Nov 1989 & 64.19 & 61.32 & 12 Jan 1990 & 34225 & 17 May 2002 & 61.00 & 63.01 & 13 Mar 2004 \\
\hline 8911517 & 3 Nov 1989 & 64.31 & 61.99 & 15 Dec 1989 & 39097 & 19 Jan 2003 & 62.12 & 60.09 & 21 Feb 2003 \\
\hline 8911521 & 3 Nov 1989 & 64.31 & 61.99 & 6 Apr 1990 & 39113 & 19 Jan 2003 & 61.92 & 59.60 & 26 Jan 2003 \\
\hline 8911516 & 5 Nov 1989 & 63.90 & 61.21 & 4 May 1990 & 39112 & 20 Jan 2003 & 61.76 & 58.99 & 15 Jun 2003 \\
\hline 8911511 & 10 Nov 1989 & 64.56 & 62.27 & 31 Aug 1990 & 39131 & 20 Jan 2003 & 61.56 & 58.57 & $24 \mathrm{Jul} 2003$ \\
\hline 8911514 & 10 Nov 1989 & 64.34 & 61.67 & 29 Aug 1990 & 39110 & 22 Jan 2003 & 61.78 & 57.04 & 4 Aug 2003 \\
\hline 8911515 & 10 Nov 1989 & 64.26 & 61.27 & 11 Nov 1989 & 39119 & 22 Jan 2003 & 61.51 & 57.53 & 17 Feb 2003 \\
\hline 8911523 & 10 Nov 1989 & 64.26 & 61.24 & 18 Nov 1989 & 39132 & 22 Jan 2003 & 61.23 & 57.23 & 19 Feb 2003 \\
\hline 8911526 & 10 Nov 1989 & 64.39 & 61.67 & 12 Nov 1989 & 39096 & 23 Jan 2003 & 61.54 & 56.60 & 25 Jan 2004 \\
\hline 8911522 & 11 Nov 1989 & 64.07 & 61.83 & 26 Feb 1990 & 39133 & 23 Jan 2003 & 61.24 & 56.53 & 16 May 2003 \\
\hline 8911520 & 16 Nov 1989 & 64.57 & 62.41 & 31 Dec 1989 & 39140 & 13 Feb 2003 & 61.23 & 60.00 & 21 Jun 2003 \\
\hline 8911510 & 19 Nov 1989 & 64.12 & 61.15 & 22 Nov 1989 & 39145 & 13 Feb 2003 & 60.96 & 60.54 & 11 Oct 2003 \\
\hline 8911525 & 19 Nov 1989 & 64.13 & 61.20 & 29 Nov 1989 & 39141 & 14 Feb 2003 & 60.03 & 58.57 & 16 Nov 2003 \\
\hline 8911513 & 22 Nov 1989 & 64.20 & 61.32 & 10 Apr 1990 & 39285 & 13 Jan 2004 & 61.02 & 60.02 & 24 Apr 2006 \\
\hline 8911527 & 22 Nov 1989 & 64.20 & 61.31 & 18 Dec 1989 & 39294 & 4 Feb 2004 & 61.05 & 58.31 & 24 Apr 2006 \\
\hline 9115852 & 7 Dec 1991 & 64.89 & 63.34 & 29 Feb 1992 & 44294 & 20 Feb 2004 & 61.25 & 57.99 & 19 Mar 2004 \\
\hline 9115849 & 13 Dec 1991 & 64.17 & 61.56 & 23 Jan 1992 & 44295 & 20 Feb 2004 & 61.25 & 57.99 & 27 Dec 2004 \\
\hline 9115853 & 22 Dec 1991 & 63.74 & 61.62 & 6 Feb 1992 & 44293 & 21 Feb 2004 & 61.01 & 58.16 & 19 Jul 2007 \\
\hline 9115850 & 25 Dec 1991 & 63.51 & 61.44 & 29 Feb 1992 & 43573 & 27 Feb 2004 & 60.08 & 55.08 & 18 Jul 2004 \\
\hline 9115832 & 29 Dec 1991 & 63.83 & 61.30 & 28 Feb 1992 & 39292 & 10 Mar 2004 & 61.01 & 56.20 & 7 Jun 2006 \\
\hline 9115846 & 2 Jan 1992 & 63.96 & 61.76 & 21 Jan 1992 & 54146 & 8 Jan 2005 & 63.61 & 67.66 & 11 Jun 2005 \\
\hline 9115845 & 3 Jan 1992 & 64.17 & 61.66 & 29 Feb 1992 & 54145 & 11 Jan 2005 & 64.78 & 64.72 & 11 Apr 2005 \\
\hline 9115833 & 4 Jan 1992 & 64.91 & 64.63 & 19 Feb 1992 & 54159 & 12 Jan 2005 & 64.57 & 65.37 & 20 Jun 2005 \\
\hline 9115840 & 4 Jan 1992 & 64.92 & 64.99 & 28 Feb 1992 & 54154 & 13 Jan 2005 & 64.82 & 64.02 & 20 Jan 2005 \\
\hline 9115844 & 4 Jan 1992 & 64.89 & 64.84 & 25 Jan 1992 & & & & & \\
\hline 9115847 & 6 Jan 1992 & 63.68 & 59.78 & 29 Feb 1992 & & & & & \\
\hline 9422046 & 21 Jan 1995 & 62.25 & 56.99 & 13 Jun 1995 & & & & & \\
\hline 9422047 & 21 Jan 1995 & 61.48 & 57.01 & 16 Aug 1995 & & & & & \\
\hline 9812322 & 22 Jan 2000 & 66.61 & 72.70 & 30 Nov 2000 & & & & & \\
\hline
\end{tabular}

in the region, the schematic circulation near the tip of the Antarctic Peninsula has been updated from Heywood et al. (2004) as shown in Fig. 3. We expect the depth-averaged circulation to be similar, at least in structure, to the surface circulation due to the weak stratification in this region. Hydrographic measurements in the western Weddell Sea consistently show that current velocities, especially those related to the frontal currents, are largely uniform throughout the water column above the thin deep outflow (e.g., Muench and Gordon 1995; TH08). Strong topographical steering of the surface drifters, as discussed in section $4 \mathrm{~b}$, supports this assumption.

The new features shown in Fig. 3 largely involve regions of divergence or convergence in the mean flow. Therefore, it is important to note that drifters are quasiLagrangian and may not follow a single water mass because they are drogued at a constant depth. In the following section, we describe the prominent features of the circulation arising from this study.

\section{a. East of the peninsula}

The deployment transect was selected to follow the WOCE section SR04 (e.g., Fahrbach et al. 1994), where there is a long record of hydrographic and mooring data. Figure 4 shows the depth-averaged (to $700 \mathrm{~m}$ ) velocity vectors along the ADELIE transect as measured by the SADCP shortly after drifter deployment (see section 2). Tidal velocities have been removed using the Earth\&Space Research/Oregon State University (ESR/OSU AntPen) ( 2-km high-resolution Antarctic Peninsula domain) high-latitude barotropic tide model (Padman et al. 2002). Vectors are colored according to (i) sea surface temperature and (ii) sea surface salinity. Over most of the transect, the velocity vectors are consistent with depth. The most strongly barotropic regions in the SADCP data coincide with the ASF and the Weddell Front, in agreement with the hydrographic data of TH08. Greater vertical variability is observed in the region of weak velocities found between the ASF 


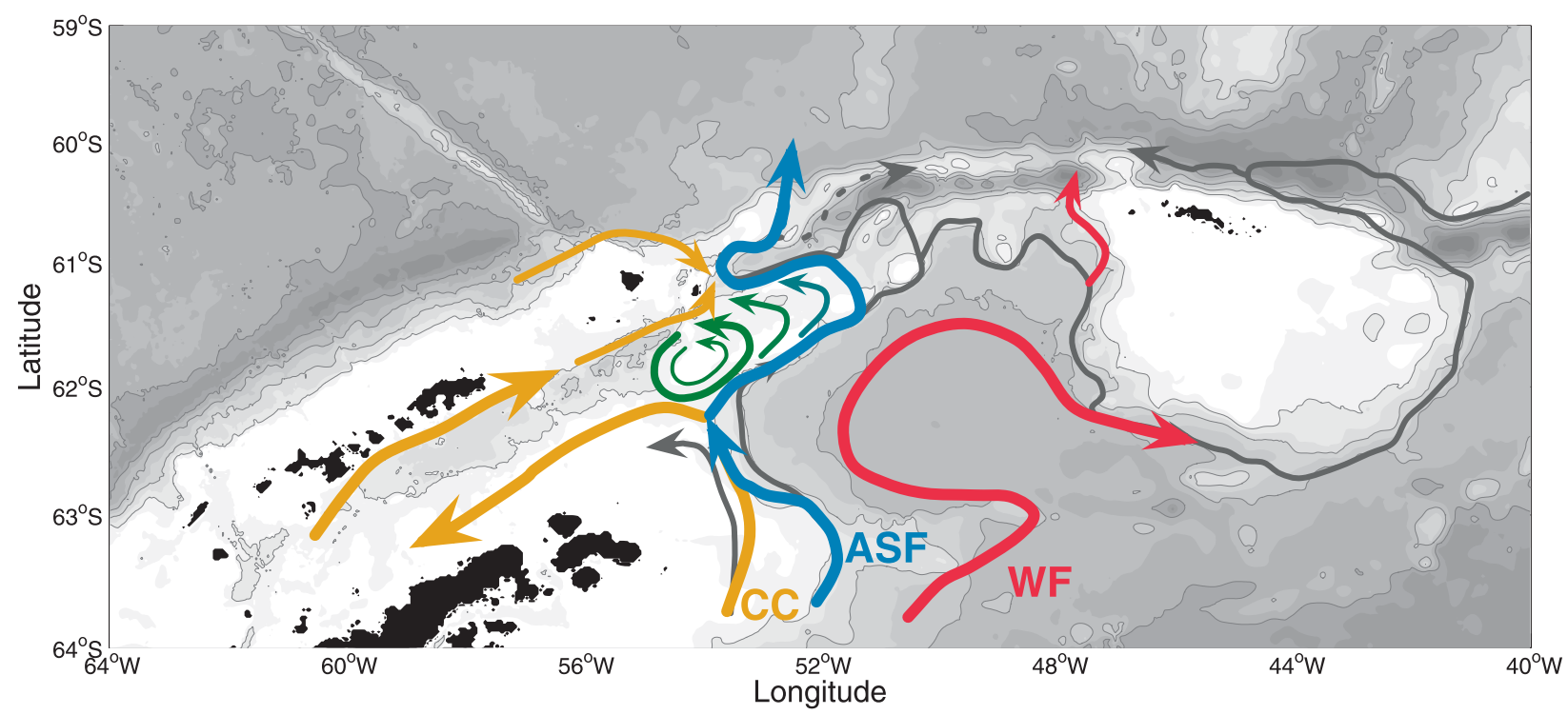

FIG. 3. Schematic of the surface currents near the Antarctic Peninsula as determined from surface drifter data. The positions of the CC, ASF, and the Weddell Front (WF) along the ADELIE deployment transect are labeled. The thick gray curves show the paths of the currents as shown in the schematic by Heywood et al. (2004). The contours and shading indicate bottom topography; colors change every $500 \mathrm{~m}$, and contours are drawn every $1000 \mathrm{~m}$ between 1000- and 4000-m depth.

and the Weddell Front in Fig. 4. While this variation with depth partially contributes to the small depth-averaged velocity here, the speeds are also small throughout the water column. The SADCP data are mainly provided to identify the location of the fronts near the drifter deployment.

The CC and ASF are visible as distinct currents located over the continental shelf and shelf break, respectively (Fig. 4). These currents are separated by a region of warm sea surface temperature. The currents are even more distinct in the sea surface salinity signal, with the $\mathrm{CC}$ having relatively high salinity values, while the ASF is relatively fresh. This follows the classic description of the ASF as a river of cold and freshwater (Gill 1973). A third front, typically associated with the deep outflow of dense water between 2000 and $3000 \mathrm{~m}$ (Muench and Gordon 1995; TH08), has a weak signature in the SADCP and is identified here by low surface salinity values. TH08 have suggested that this current is related to the Weddell Front typically observed south of the South Orkney Plateau (see also Fig. 3).

Figure 5 shows three snapshots of the ADELIE drifter trajectories during the first month following deployment. In Fig. 5a the positions of the CC, the ASF, and the Weddell Front are apparent from the three regions of extended drifter trajectories. There is a clear distinction between drifters deployed shoreward of the 2500-m isobath, which move to the northwest and become entrained in the ASF, and drifters deployed in deeper waters, which enter Powell Basin. Drifters de- ployed in the ASF show a large degree of topographic steering within the first week as they turn toward the northwest to follow the 1000 -m isobath. Drifter trajectories in Figs. 5b,c further confirm the role of topographic steering throughout the drifter array. In particular, drifters deployed in water with depths up to $3000 \mathrm{~m}$ show a remarkable tendency to follow isobaths as they move around the tip of Joinville Ridge and abruptly turn westward before entering Powell Basin. This rapid change in direction is unlikely to be caused by Ekman velocities resulting from a large wind event because the westward velocities persist over a period of a week or longer. The other important feature in Fig. $5 \mathrm{c}$ is the merging of the $\mathrm{CC}$ and the ASF around $62.5^{\circ} \mathrm{S}$, prior to these currents reaching the South Scotia Ridge. These currents merge before any drifters enter Bransfield Strait.

Drifters deployed between the CC and ASF have large velocities that are dominated by eddying motions that do not result in a large displacement from the deployment location (see also Fig. 4). In contrast, drifters deployed between the ASF and the Weddell Front are relatively stagnant as the flow splits westward toward the ASF and eastward around Joinville Ridge (see SADCP data near $51^{\circ} \mathrm{W}$; Fig. 4).

\section{b. Antarctic Slope Front}

The dominant feature in the ADELIE drifter dataset is the ASF. Here, 27 of the 39 ADELIE drifters are either originally deployed in the ASF or become entrained within this current at some point during their 

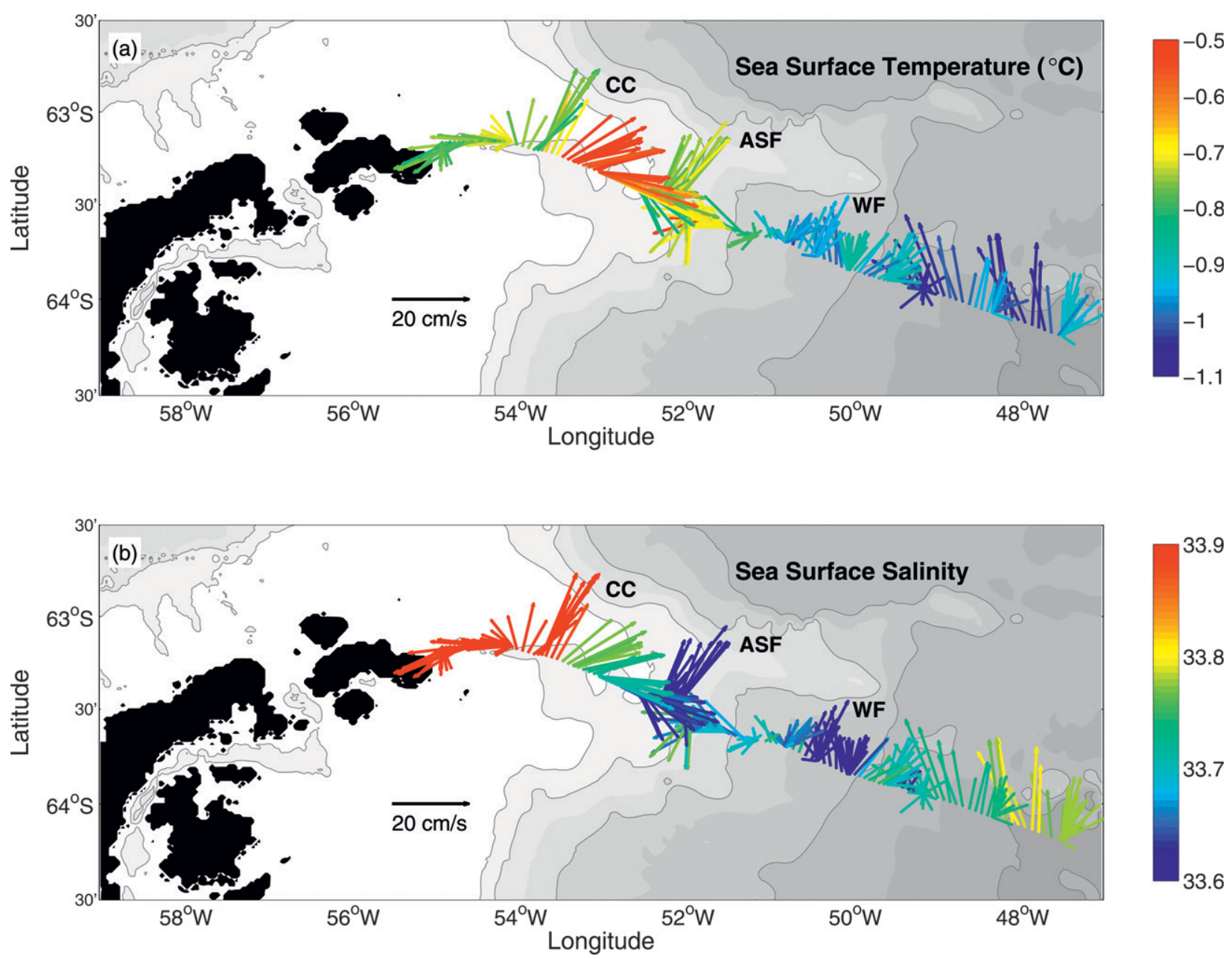

FIG. 4. SADCP velocity vectors along the drifter deployment transect (tidal velocities have been removed). The velocity scale is given by the black arrows. The velocity vectors are colored by (a) SST $\left({ }^{\circ} \mathrm{C}\right)$ and (b) sea surface salinity as measured at 6 -m depth by the underway oceanlogger on the JCR. The contours and shading indicate bottom topography; color changes every $500 \mathrm{~m}$, and contours are drawn at $500 \mathrm{~m}$ and then every $1000 \mathrm{~m}$ between 1000 and $4000 \mathrm{~m}$. Positions of the CC, ASF, and WF are labeled.

trajectories. Drifters deployed over the continental shelf may undergo a number of oscillations before entering the ASF, suggesting eddy trapping. Trajectories within the ASF are concentrated along the $1000-\mathrm{m}$ isobath until reaching the South Scotia Ridge near $62.5^{\circ} \mathrm{S}$ (Fig. 5c).

Upon reaching the South Scotia Ridge, the topography becomes more complicated: isobaths turn to the northeast along the southern boundary of the South Scotia Ridge and a deep canyon extends to the southwest into Bransfield Strait from the western edge of the South Scotia Ridge. Drifters within the ASF undergo one of three possible fates at the western edge of the South Scotia Ridge (approximately $62.5^{\circ} \mathrm{S}$ and $54^{\circ} \mathrm{W}$ ); these are depicted in Fig. 6.

The first possible fate is that drifters may be carried westward into Bransfield Strait where they follow the southern boundary of the canyon. ADELIE drifters that entered Bransfield Strait eventually drifted into shallow waters near the peninsula. Zhou et al. (2006) have shown that the northern region of Bransfield Strait contains a strong western boundary current where velocities can exceed $50 \mathrm{~cm} \mathrm{~s}^{-1}$. Tracers entering Bransfield Strait from the east may be recirculated toward the South Scotia Ridge along this western boundary current. The formation of sea ice within Bransfield Strait during the period when the ADELIE drifters were close to the continent limited their movement. However, the ADELIE drifters did occupy similar locations to the drifters deployed by Zhou et al. (2002), which were entrained into and transported eastward by the western boundary current.

A second possible fate of drifters within the ASF is that they become entrained in a large standing eddy 

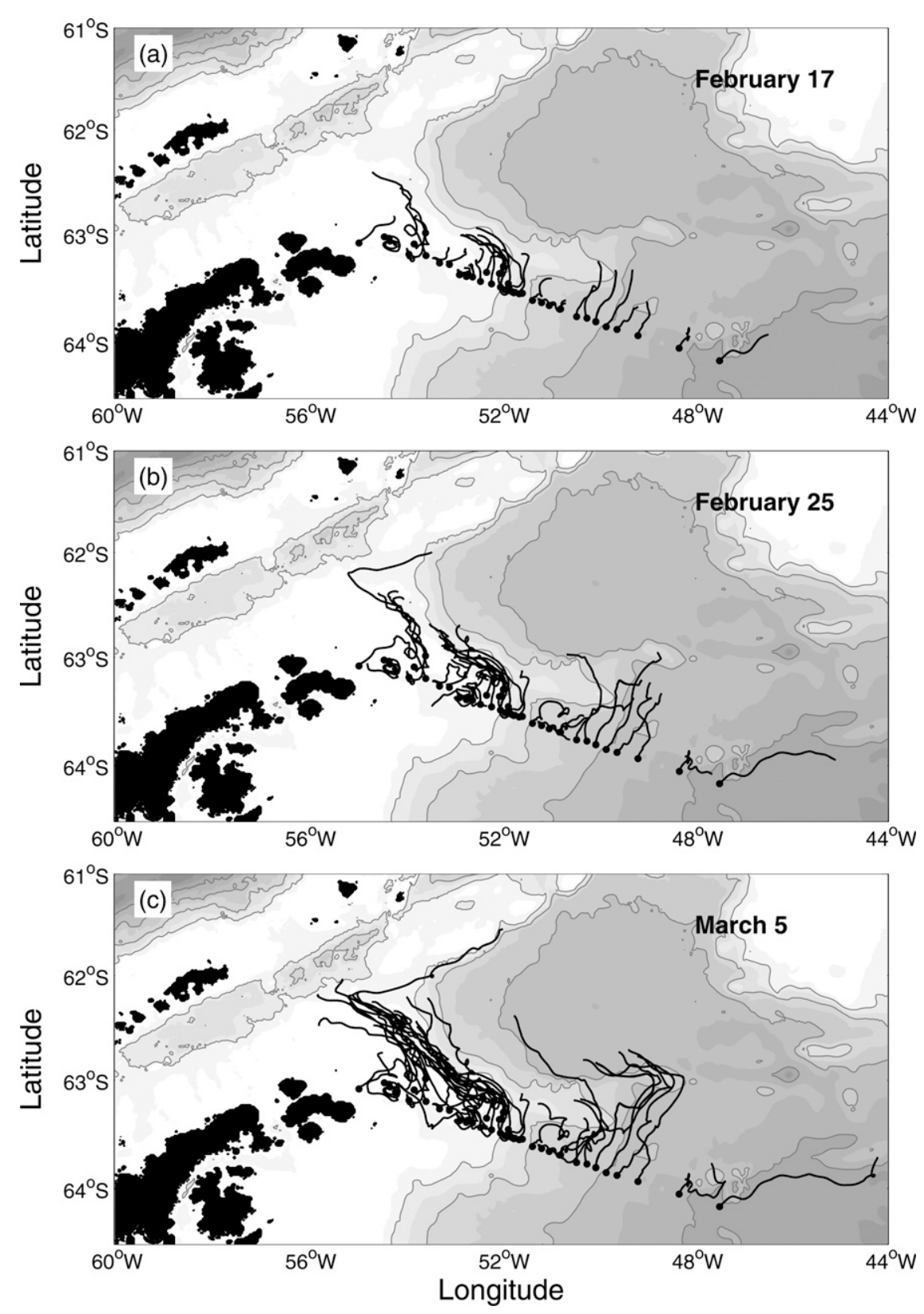

FIG. 5. Filtered trajectories of the 39 ADELIE drifters at (a) 8, (b) 16, and (c) 24 days after deployment (dates given in each panel). The dots represent the deployment locations (or in some cases the first fix when there was a delay with the GPS drifters). The gray curves indicate the 1000-, 2000-, 3000-, and 4000-m isobaths.

located over the South Scotia Ridge centered at $62^{\circ} \mathrm{S}$ and $54^{\circ} \mathrm{W}$. The size of this recirculation feature is approximately $40 \mathrm{~km}$ in diameter, thus exceeding the Rossby deformation radius, which is approximately 10 $15 \mathrm{~km}$ at this latitude (Chelton et al. 1998). Drifters are entrained into this region principally from the west and north and may remain trapped here for as long as a month. The circulation is anticyclonic, as expected by conservation of potential vorticity over a local rise in bottom topography (Vallis and Maltrud 1993). This feature is also observed in the historical drifter trajectories, which span a period of $15 \mathrm{yr}$, suggesting that this eddy is a permanent feature of the surface circulation. This standing eddy may be dynamically significant for the mixing and transport of tracers because it generates regions of strong horizontal shear both near the split- 


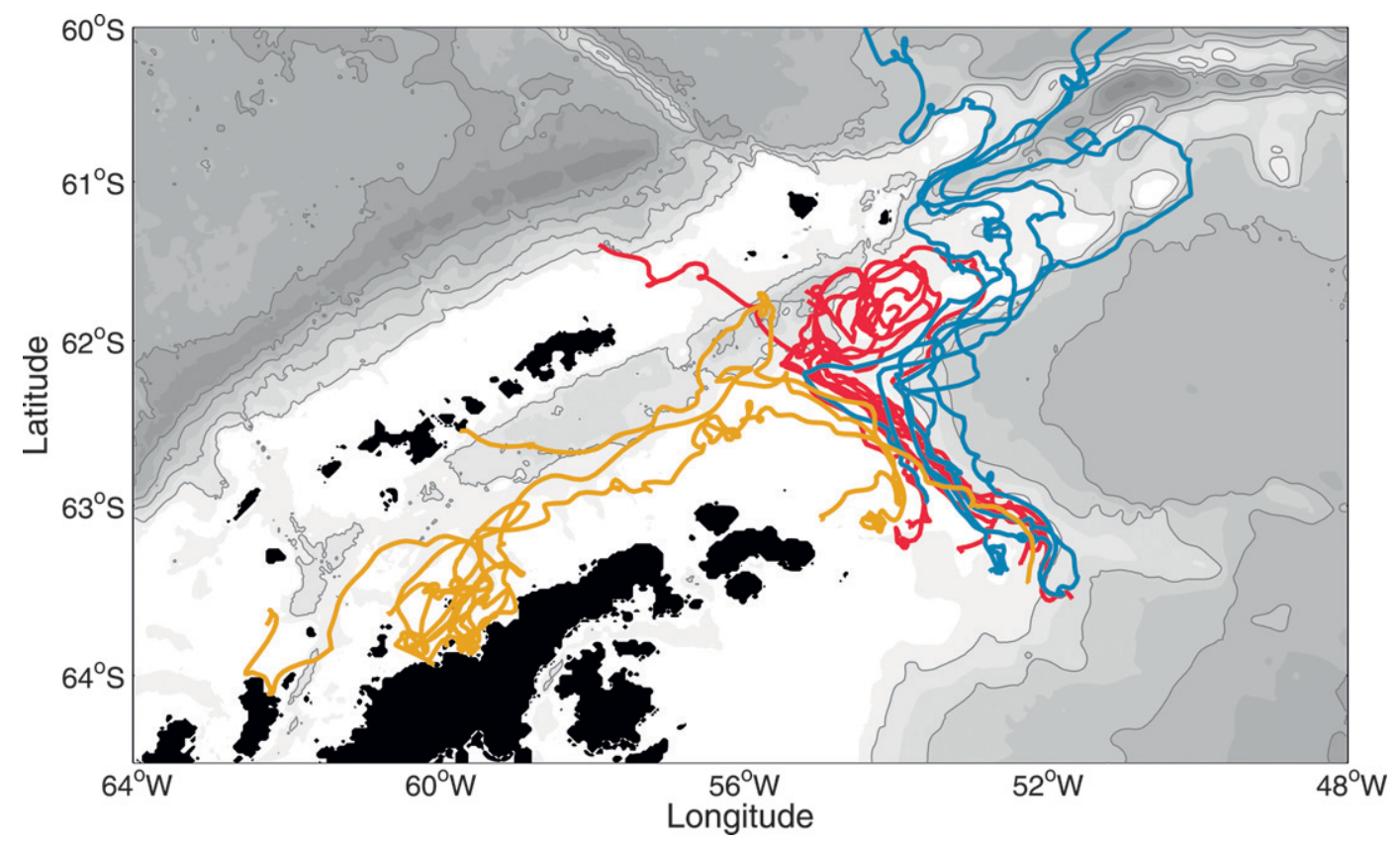

FIG. 6. Filtered trajectories of the ADELIE drifters entrained into the ASF near the tip of the Antarctic Peninsula. The colors indicate the three different fates of these drifters after the ASF bifurcates upon reaching the South Scotia Ridge. Drifters are either carried west into the southern part of Bransfield Strait (gold trajectories), entrained in an anticyclonic eddy (red trajectories), or move to the east and eventually escape to the north through the Weddell-Scotia Confluence (blue trajectories).

ting of the ASF at the western edge of the South Scotia Ridge and along its northern boundary where the western boundary current of Bransfield Strait flows into the Weddell Scotia Confluence. This feature is discussed further in section 5 .

The third possible fate of drifters within the ASF is that they are carried eastward along the 1000- $\mathrm{m}$ isobath on the southern boundary of the South Scotia Ridge. At the eastern edge of the South Scotia Ridge the bathymetry becomes complex with a number of gaps and passages providing the possibility for drifters to escape into the ACC. ADELIE drifters that followed this route had complicated trajectories that largely followed isobaths, avoiding flow across steep slopes such as the Hesperides Trough. Each of these trajectories passes very close to Clarence Island on its eastern side. Drifters exiting from Bransfield Strait also tend to pass close to the eastern coast of Clarence Island. Figure 7 shows the subset of ADELIE and historical drifters that pass through the Weddell Scotia Confluence and escape into the ACC. Drifter trajectories may enter the boxed region of Fig. 7 from the western Weddell Sea, from Bransfield Strait, or from the area around the South Shetland Islands (solid black curves). However, the drifters leave the Weddell Scotia Confluence and enter the ACC only through a small portion of the northern boundary of the box, princi- pally along the northern boundary of the Hesperides Trough. Therefore, the region east of Clarence and Elephant Islands acts as a choke point for flow leaving the Weddell Scotia Confluence and entering the ACC. Because water flows into this region from a variety of sources, important changes in water mass properties may occur if mixing is prevalent.

As shown in Fig. 6, the fate of drifters entrained in the ASF is not determined by deployment location. Drifters deployed over the continental shelf out to the 2000-m isobath realize all three possible fates. This suggests that transient dynamics, such as eddies or wind events, and perhaps even tides, may ultimately play a key role in determining the paths of tracers at the point where the drifter trajectories diverge at the South Scotia Ridge.

\section{c. Powell Basin}

Drifters deployed seaward of the 2500-m isobath all entered Powell Basin following a cyclonic path (Fig. 2). The tendency to form cyclonic currents around topographical depressions follows from Holloway's (1992) Neptune effect, and it has recently been used to explain the formation of cyclonic and anticyclonic surface drifter trajectories in the Aegean Sea (Olson et al. 2007). The ADELIE drifters carried into Powell Basin suffered the most from the delay in the research cruise 


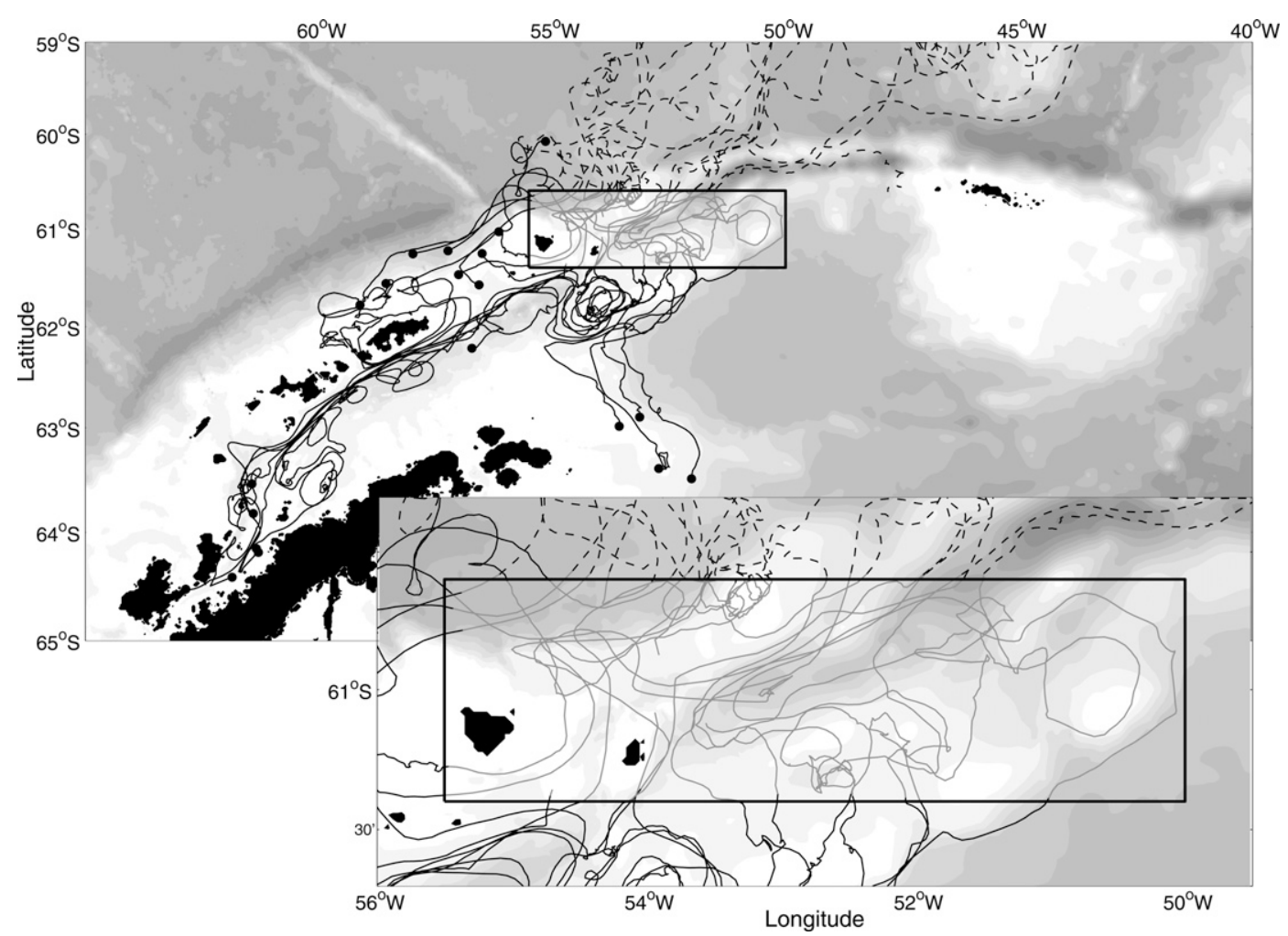

FIG. 7. ADELIE and historical drifter trajectories near the tip of the Antarctic Peninsula that escape into the Antarctic Circumpolar Current. The box in the larger panel is an important choke point for particles leaving the Weddell Sea; this region is expanded in the bottom panel. The solid black curves represent drifter trajectories prior to entering the box, while the dashed black portions of the curves are the trajectories after exiting the box. In some cases, a drifter trajectory will enter and exit the box multiple times. For these trajectories, the curve is only solid until the drifter first enters the box. The dots indicate deployment locations. Shading indicates bottom topography as in Fig. 1.

because the drifters were captured by sea ice before they could reach the southern shelf of the South Orkney Plateau. Drifter velocities are slower in Powell Basin, possibly reflecting weaker topographic forcing due to the greater depth of the water column. Drifter trajectories within Powell Basin remain separate from those found along the South Scotia Ridge. This further supports the view that the ASF and the Weddell Front are distinct currents as discussed by TH08. Furthermore, the ADELIE drifter trajectories suggest that water masses found within and shoreward of the ASF remain shielded from Powell Basin through topographical steering.

\section{Drifter statistics}

It is apparent from the drifter trajectories that topography near the tip of the Antarctic Peninsula plays a significant role in steering the circulation, even near the surface. In this section, we provide a statistical analysis of the drifter data, and in particular, we quantify the tendency for drifters to spread along and across contours of $f / h$.

The velocities derived from the surface drifters contain both geostrophic and ageostrophic components, with the latter dominated by wind-driven flow. It is perhaps most convincing to argue that the wind-driven component was small during this study by considering how closely the drifter trajectories followed topographical features. However, to confirm this, we obtained $12-\mathrm{m}$ wind data on a $20-\mathrm{km}$ grid from the Antarctic Mesoscale Prediction System (AMPS) for the months of February through June 2007. With these wind data, we calculated both Ekman velocities and the Stokes drift component at 15-m depth using Eq. (1) of Niiler et al. (2003) and Eq. (66) of McWilliams and Restrepo (1999), respectively. Both of these components were found to be small with peak values consistently around $1 \mathrm{~cm} \mathrm{~s}^{-1}$, which is less than the expected drogue slip. The work of Rio and Hernandez (2003) confirms that Ekman velocities are small near the tip of the Antarctic Peninsula, although there is not coverage 
for the entire area of the ADELIE study. Because wind data are unavailable for the entire drifter record or for the historical drifters, the wind component has not been removed. We note that the mean current estimates often involve averages over observations at very different times, and thus the wind-driven component would tend to be minimized unless the wind direction was consistently in a uniform direction.

\section{a. Basic flow statistics}

The velocity observations were averaged in bins of $0.2^{\circ}$ latitude $\times 0.4^{\circ}$ longitude to obtain estimates of the large-scale mean circulation during the measurement period. A distance of $0.4^{\circ}$ of longitude at $65^{\circ} \mathrm{S}$ is approximately $19 \mathrm{~km}$, while $0.4^{\circ}$ of longitude at $59^{\circ} \mathrm{S}$ is approximately $23 \mathrm{~km}$, thus the bins are roughly square throughout the domain $\left(0.2^{\circ}\right.$ latitude $\left.\approx 22 \mathrm{~km}\right)$. We have chosen to incorporate 55 historical drifters that entered the region $65^{\circ}$ to $40^{\circ} \mathrm{W}$ and $65^{\circ}$ to $59^{\circ} \mathrm{S}$. The introduction of the historical data complements the observations made by the ADELIE drifters because it provides supporting data in regions, such as Bransfield Strait, where sampling by ADELIE drifters was less dense. We note that more sophisticated methods exist for determining the mean circulation, such as objective analysis (Davis 1998) or bicubic spline interpolation (Bauer et al. 1998), but for simplicity binned means were applied. ${ }^{4}$

Figure 8 shows the mean circulation derived from (i) the ADELIE drifters, (ii) the historical drifters, and (iii) the combined drifter dataset. The two sets cover very different regions of the northwestern Weddell Sea, but taken together they provide a relatively complete view of the surface circulation in this area. The clearest features are the strong ASF northeast of Joinville Island, the western boundary current in Bransfield Strait, the standing eddy over the South Scotia Ridge, and the convergence of flow near Elephant and Clarence Islands. These latter two features are expanded in Fig. 9, which corresponds to the boxed region in Fig. 8c. Figure 9 uses bins that are $0.1^{\circ}$ latitude $\times 0.2^{\circ}$ longitude. At this increased resolution, regions of strong horizontal shear (e.g., the western edge of the South Scotia Ridge and along the Hesperides Trough) are clearly visible.

Velocity estimates are assumed to be independent if they are separated by times longer than the Lagrangian time scale. Assuming that the eddy field is

\footnotetext{
${ }^{4}$ Falco et al. (2000) found that there was little difference between mean circulations derived from binned means and bicubic spline interpolation in the Adriatic Sea.
}

homogeneous and stationary, the eddy diffusivity $\kappa$ is defined as

$$
\kappa=\lim _{t \rightarrow \infty} \varkappa, \varkappa(t) \equiv \int_{0}^{t} R(\tau) \mathrm{d} \tau,
$$

where $R(\tau)$ is the Lagrangian autocovariance of the eddy velocity (Bauer et al. 1998; Falco et al. 2000). The Lagrangian time scale $T_{L}$ is then obtained by dividing $\kappa$ by the variance of the eddy velocity $\sigma^{2}$, or

$$
T_{L}=\frac{1}{\sigma^{2}} \int_{0}^{\infty} R(\tau) \mathrm{d} \tau .
$$

Figure 10 shows the autocovariance $R$ (thin curve) and eddy diffusivities $\kappa$ (bold curve) in both (i) zonal and meridional geographic components and (ii) along and across $f / h$ components for both ADELIE and historical drifters. In both cases $\kappa$ asymptotes to a constant value within approximately 10 days. The Lagrangian time scale $T_{L}$ is approximately one day for the ADELIE drifters and slightly longer for the historical drifters. This value is comparable to other drifter studies in coastal and topographically influenced regions such as the Adriatic Sea (Falco et al. 2000) and the Aegean Sea (Olson et al. 2007). The Lagrangian scales are summarized in Table 3.

Figure 11a shows the number of independent observations that are available from the combined historical and ADELIE drifters based on the Lagrangian timescale estimates. Velocity observations are only separated into mean and eddy components if they are found in a bin with five or more independent observations. Figure 11b shows the eddy kinetic energy (EKE) derived from the binning process described above. The largest values of EKE are found north of the South Scotia Ridge, where strong currents along the southern boundary of the ACC impinge on the Weddell Scotia Confluence. Here, maximum values of the EKE can reach $700 \mathrm{~cm}^{2} \mathrm{~s}^{-1}$. Typical values within the Weddell Gyre are much smaller, peaking around $250 \mathrm{~cm}^{2} \mathrm{~s}^{-1}$ along the ASF and up onto the South Scotia Ridge. The standing eddy shown in Fig. 9 is not correlated with a peak in EKE, suggesting that there is little variability associated with this feature (see discussion in section $3 \mathrm{~b}$ ). We note that mean velocities to the east of the Peninsula are generated solely from ADELIE drifters, and thus the EKE reflects variability at meso- and synoptic scales, but not seasonal or interannual variability. Historical drifters in Bransfield Strait and the Weddell Scotia Confluence have been deployed in various years, and therefore EKE here may represent longer temporal variability. Figure 11c shows the mean kinetic energy for comparison with the EKE. The signal is dominated 

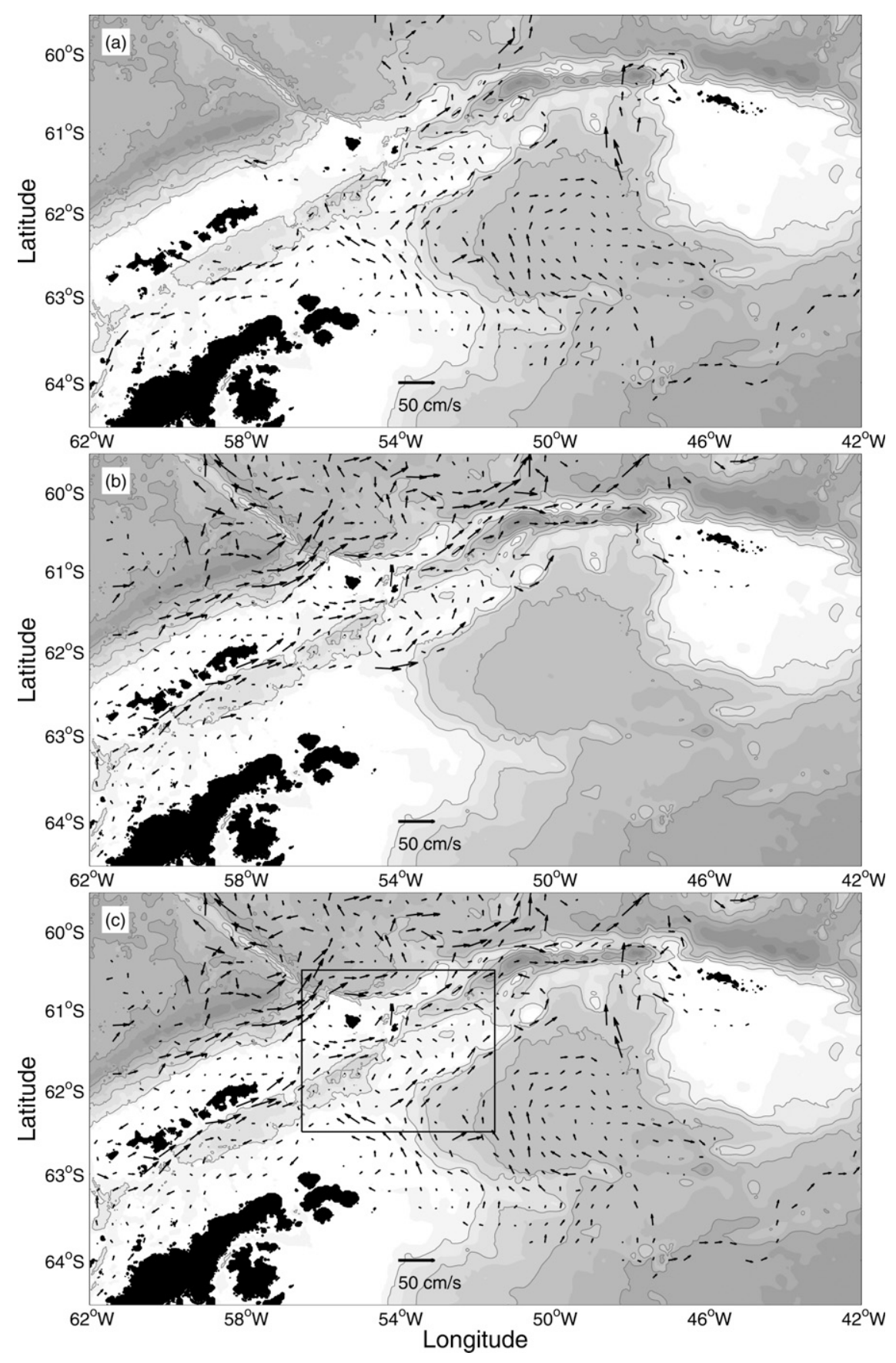

FIG. 8. The mean velocity field for (a) the ADELIE surface drifters, (b) the historical surface drifters, and (c) the combined ADELIE and historical surface drifter dataset. The bin size is $0.2^{\circ}$ lat $\times 0.4^{\circ}$ lon. The shading indicates bathymetry with color change every $500 \mathrm{~m}$ and contour lines at every $1000 \mathrm{~m}$ between 1000- and 4000-m depth. The region enclosed by the box in (c) is expanded in Fig. 9.

by the strong slope front currents in the northern part of Bransfield Strait and along the southern boundary of the South Scotia Ridge.

Because the number of independent measurements in some grid boxes is relatively low, we present our error estimates in Fig. 12 in the form of $95 \%$ confidence intervals for both the mean currents (top) and the EKE (bottom). The confidence intervals are calculated using a bootstrapping technique in which binned observations are subsampled randomly and averaged 100 times 


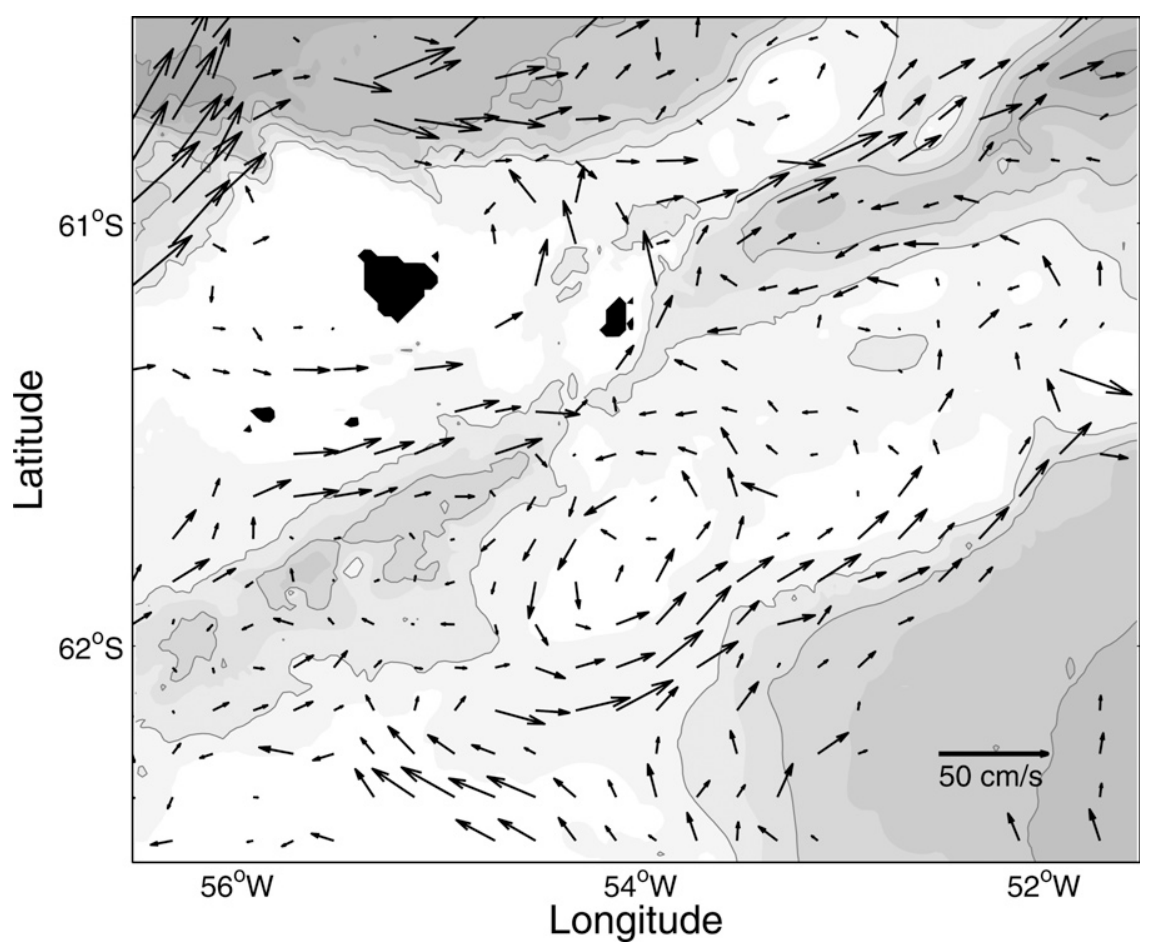

FIG. 9. Expanded view of the mean circulation in the boxed region of Fig. $8 \mathrm{c}$ with a reduced bin size of $0.1^{\circ}$ lat $\times 0.2^{\circ}$ lon. This region is well populated by both ADELIE and historical surface drifters so that the mean circulation from the reduced bin size remains robust.

using one-half of the available data in each bin. The top panels show the difference $\Delta$ from the mean flow in both zonal and meridional directions ( $\Delta$ is obtained by taking the mean of the differences between the 50th and the 97 th and the 50th and the 3rd percentiles in the bootstrapping distribution). Lower and upper bounds of the EKE confidence intervals correspond to the 3rd and 97th percentiles of the bootstrapping distribution respectively.

\section{b. Steering by $f / h$}

In this section we analyze the extent to which drifters are steered by contours of $f / h$. We consider contours of $f / h$ to make a connection with the importance of poten-
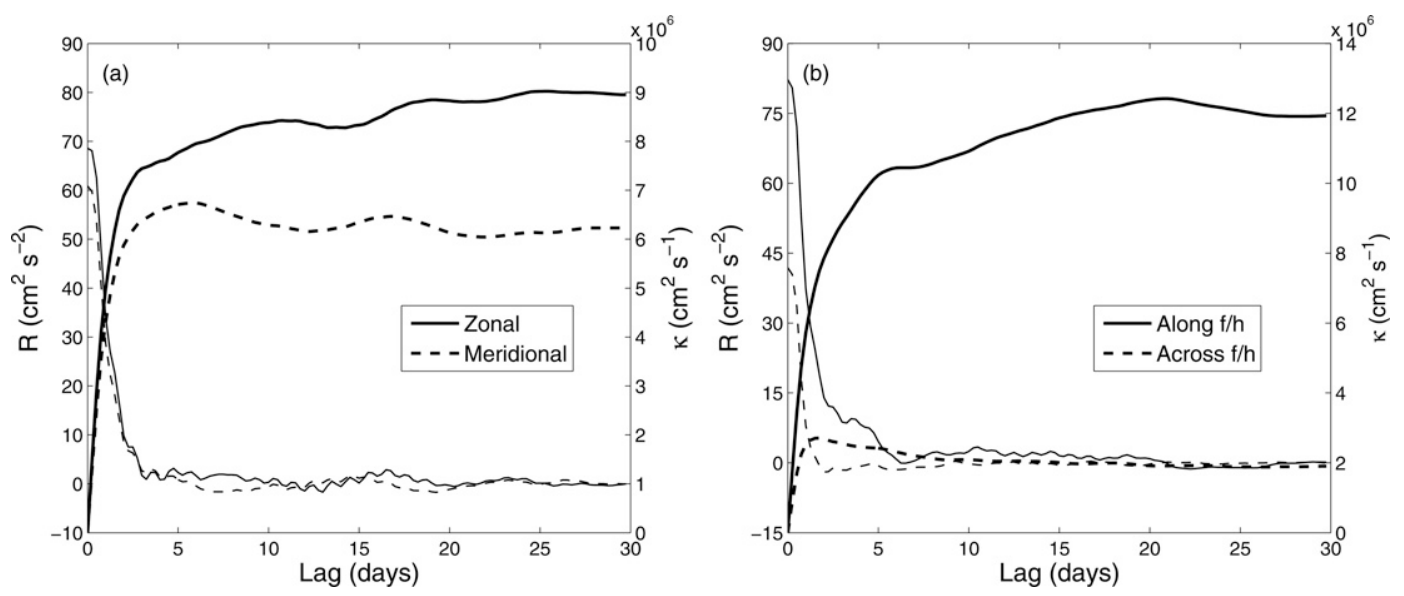

FIG. 10. Autocovariances $R$ (thin curves) and eddy diffusivities $\kappa$ (bold curves) for the (a) zonal and meridional eddy velocities and (b) along- and across-f/h eddy velocities following the mean eddy decomposition of the combined ADELIE and historical surface drifter dataset. 
TABLE 3. Lagrangian time and length scales $(T, L)$, velocity variances $\left(\left\langle\mathbf{u}^{2}\right\rangle\right)$, where \langle\rangle indicates a spatial and temporal average, and diffusivities $\kappa$ for geographic and $f / h$ coordinates. The data are given for the ADELIE drifters, the historical drifters, and the combined drifter dataset.

\begin{tabular}{|c|c|c|c|c|c|c|c|c|}
\hline Geographic & $\begin{array}{c}T_{u} \\
\text { (days) }\end{array}$ & $\begin{array}{c}T_{v} \\
\text { (days) }\end{array}$ & $\begin{array}{c}L_{u} \\
(\mathrm{~km})\end{array}$ & $\begin{array}{c}L_{v} \\
(\mathrm{~km})\end{array}$ & $\begin{array}{c}\left\langle u^{\prime 2}\right\rangle \\
\left(\mathrm{cm}^{2} \mathrm{~s}^{-2}\right)\end{array}$ & $\begin{array}{c}\left\langle v^{\prime 2}\right\rangle \\
\left(\mathrm{cm}^{2} \mathrm{~s}^{-2}\right)\end{array}$ & $\begin{array}{l}\kappa_{u} \times 10^{6} \\
\left(\mathrm{~cm}^{2} \mathrm{~s}^{-1}\right)\end{array}$ & $\begin{array}{l}\kappa_{v} \times 10^{6} \\
\left(\mathrm{~cm}^{2} \mathrm{~s}^{-1}\right)\end{array}$ \\
\hline ADELIE & 1.35 & 0.73 & 8.12 & 4.28 & 48.7 & 46.3 & 5.66 & 2.91 \\
\hline Historical & 1.58 & 1.40 & 12.5 & 10.2 & 82.9 & 71.3 & 11.4 & 8.62 \\
\hline Combined & 1.49 & 1.18 & 10.7 & 7.97 & 68.6 & 60.9 & 8.83 & 6.22 \\
\hline$f / h$ & $T_{\text {along }}$ & $T_{\text {across }}$ & $L_{\text {along }}$ & $L_{\text {across }}$ & $\left\langle u_{\text {along }}^{\prime 2}\right\rangle$ & $\left\langle v_{\text {across }}^{\prime 2}\right\rangle$ & $\kappa_{\text {along }}$ & $\kappa_{\text {across }}$ \\
\hline ADELIE & 1.12 & 0.55 & 7.01 & 2.86 & 52.5 & 36.1 & 5.08 & 1.72 \\
\hline Historical & 1.94 & 0.52 & 17.1 & 2.99 & 103.7 & 46.0 & 17.4 & 2.03 \\
\hline Combined & 1.71 & 0.53 & 13.4 & 2.98 & 82.2 & 41.8 & 12.1 & 1.93 \\
\hline
\end{tabular}

tial vorticity conservation on the flow dynamics. However, between the latitudes $65^{\circ}$ and $59^{\circ} \mathrm{S}, f$ only changes by about $7 \%$, so topographical effects dominate. Richardson (1982) first discussed how f/h might influence near-surface drifter motion, an effect that is largely dependent on the local stratification.

We follow the method described by LaCasce and Speer (1999) by calculating the first two moments of displacement (mean displacement and dispersion) in along-f/h and across- $f / h$ directions as well as zonal and meridional directions. This method was applied to float data by LaCasce (2000) to show steering by $f / h$ in floats at various depths, including near-surface waters. A brief description of the method is given in the appendix. We note that this method simply determines the extent to which tracer transport is expected to be sensitive to $f / h$; a full discussion of the dynamics causing this steering near the Antarctic Peninsula is beyond the scope of this study.

In Fig. 13 the data are divided into ADELIE drifters, historical drifters, and these groups combined. The ADELIE drifters were released in a region where the $f / h$ contours are predominantly aligned meridionally. This is reflected in Fig. 13a, where the drifters show anisotropy in mean displacement in both geographic and $f / h$ coordinates. The dashed lines in each panel give the $95 \%$ confidence limits (as defined in the appendix) for $f / h$ coordinates, while the dotted lines are the $95 \%$ confidence limits for geographic coordinates. Thus, a statistically significant anisotropy in mean displacement develops more rapidly (after 5 days) in $f / h$ coordinates than in geographic coordinates.

Figure 13b shows the dispersion of the ADELIE drifters. There is no statistical difference between dispersion in the zonal and meridional directions; anisotropy only occurs in $f / h$ coordinates. The large dispersion in the zonal direction, despite a near-zero zonal mean displacement, is a signature of the bifurcation of the ASF on the South Scotia Ridge, which produces many dissimilar trajectories that yield a negligible mean displacement. This shows that the tendency to follow contours of $f / h$ does not preclude drifters that are initially close from realizing very different trajectories. Lagrangian instruments in the ocean are often described as spreading diffusively, in which case dispersion is expected to grow linearly after the Lagrangian time scale (Taylor 1921). The dispersion curves increase roughly linearly after the first couple of days in Figs. 13b,d,f (the Lagrangian time scales are given in Table 3).

The mean displacements for selected historical drifters are shown in Fig. 13c (these are largely the historical drifters included in Fig. 7). This is a subset of the historical drifters used to determine the mean circulation in Fig. 8, with drifter trajectories over deeper water outside of the Weddell Scotia Confluence excluded. The historical drifters typically survived for longer periods because they were released earlier in austral summer and therefore did not encounter sea ice. The zonal orientation of $f / h$ contours within Bransfield Strait coupled with the western boundary current (Zhou et al. 2002) produces a large zonal mean displacement. Mean displacement in the along- $f / h$ direction is smaller than both zonal and meridional displacements. This occurs because in the northern part of Bransfield Strait, the flow is steered by topography (Zhou et al. 2006), leading to eastward drift and positive along- $f / h$ displacement. However, north of the South Shetland Islands, the influence of the ACC carries drifters eastward with shallow topography to the right producing a negative along- $f / h$ displacement that cancels the Bransfield Strait contribution. Dispersion of the historical drifters (Fig. 13d) only has a statistically significant anisotropy in $f / h$ coordinates. Dispersion of the historical drifters is significantly larger than dispersion of the ADELIE drifters in all components, which is largely due to the increased eddy kinetic energy along the southern boundary of the ACC. 

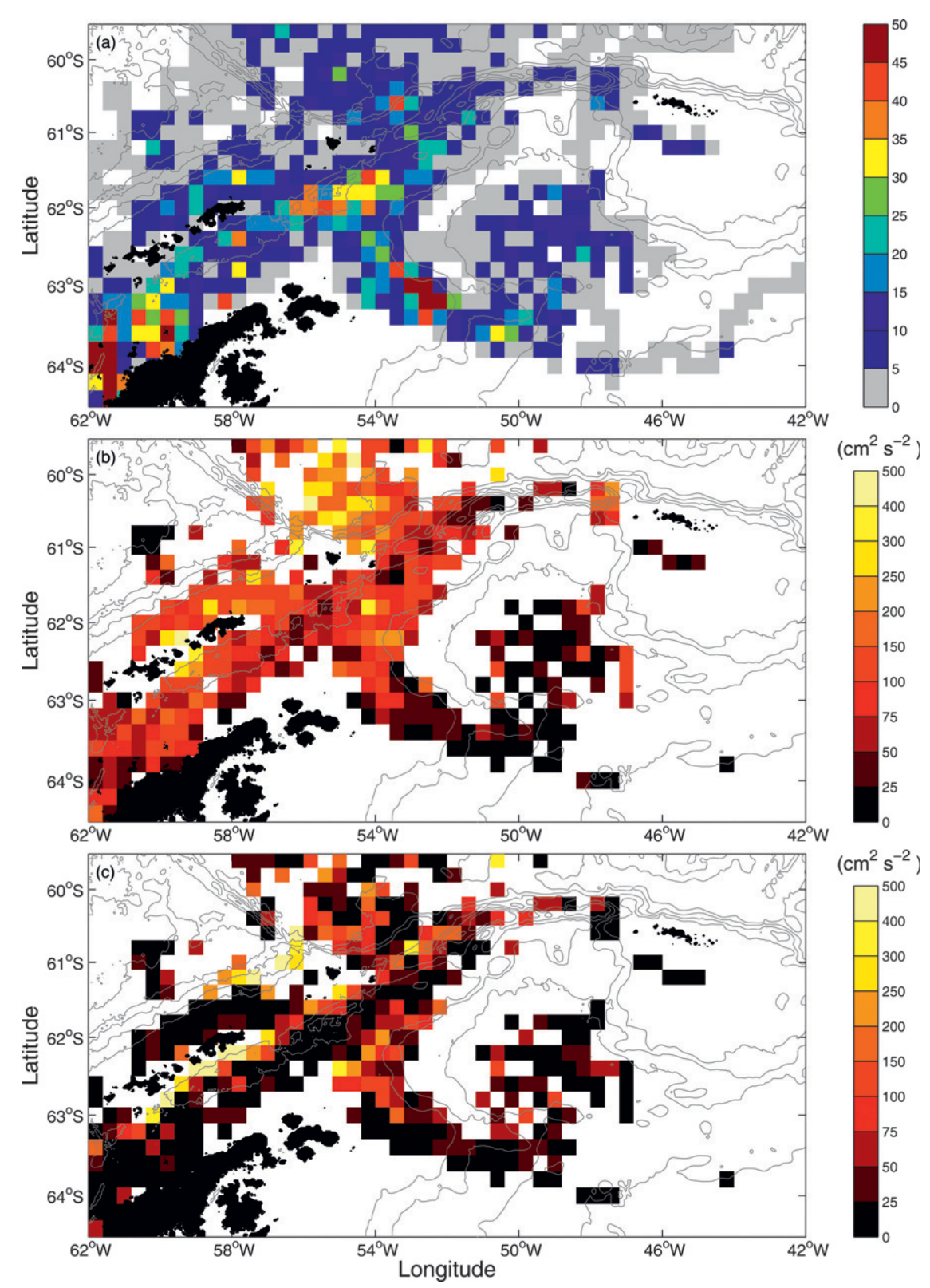

FIG. 11. (a) Number of independent velocity estimates based on the Lagrangian time scale $T_{L}$ (Bauer et al. 1998). This time scale is approximately one day (see section 4 a and Table 3 ). (b) The distribution of EKE based on the combined ADELIE and historical drifter dataset. (c) The distribution of mean kinetic eddy based on the combined ADELIE and historical drifter dataset. In both panels, the contours indicate isobaths at 1000-m intervals between 1000- and 4000-m depth.

The combined dataset yields equal mean displacement in geographic coordinates, while mean displacement remains anisotropic in $f / h$ coordinates (Fig. 13e). A weak anisotropy in dispersion is apparent in geographic coordinates after approximately 15 days (Fig. 13f); however, it does not approach the degree of anisotropy in $f / h$ coordinates, where dispersion along $f / h$ contours is an order of magnitude larger than disper- sion across $f / h$ contours. Although it is well known that coastal flows are susceptible to steering by $f / h$, it is striking the extent to which drifters drogued at $15 \mathrm{~m}$ adhere to these contours despite potentially strong contributions from tidal (Robertson 2005) and Ekman forcings (Kottmeier et al. 1992).

We next consider a mean and eddy decomposition of the drifter velocities (Davis 1991; Bauer et al. 1998). 

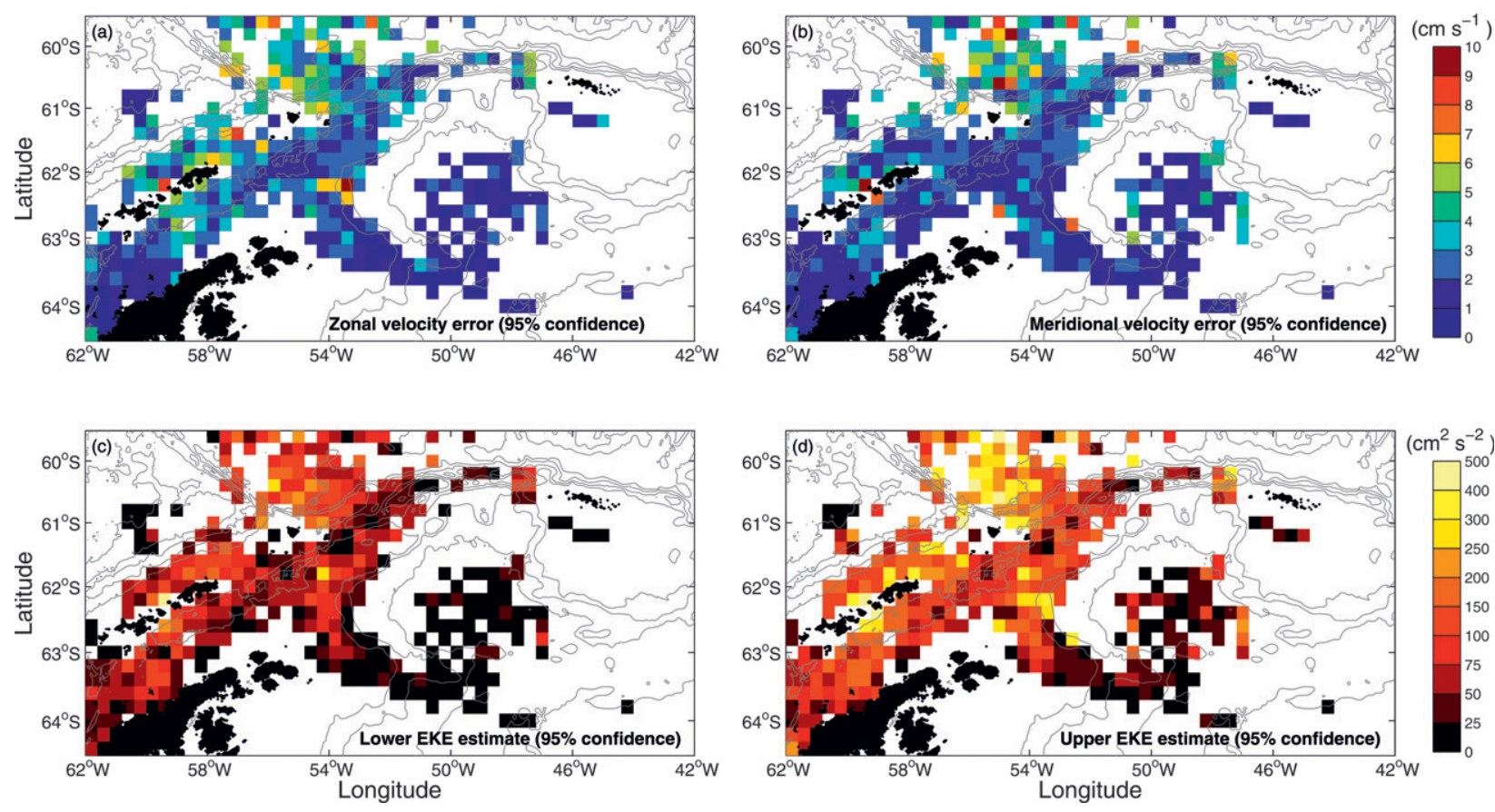

FIG. 12. Error estimates for the mean velocities and EKE. The top panels show the velocity difference $\Delta$ from the binned averages shown in Fig. $8 \mathrm{c}$ that account for the $95 \%$ confidence intervals (i.e., the $95 \%$ confidence intervals are $\overline{\mathbf{u}} \pm \boldsymbol{\Delta}$ ). Confidence intervals are given for (a) zonal and (b) meridional velocities. The bottom panels show the (c) lower and (d) upper bounds of the $95 \%$ confidence intervals of the EKE. The confidence intervals are calculated using a bootstrapping technique in which binned observations are subsampled randomly and averaged 100 times using one-half of the available data in each bin.

The mean circulation is calculated in both geographic and $f / h$ coordinates in bins with at least five independent observations (Fig. 11a). ${ }^{5}$ At the position of each velocity observation, a mean velocity is determined by spatial interpolation of the binned values. The eddy velocity is the difference between the observed and interpolated mean values. These interpolated mean and eddy velocities are integrated to calculate the first and second moments of displacement.

The top of Fig. 14 shows mean and eddy statistics in geographic coordinates, while the bottom shows mean and eddy statistics in $f / h$ coordinates; the statistics are calculated from the combined ADELIE and historical drifter dataset. ${ }^{6}$ In both coordinate frames, mean displacement due to the eddy component of the flow is not statistically different from zero (Figs. 14a,c), which is a check that the binning process is sufficient to resolve the mean flow. The clearest signal in the data is the large degree of anisotropy between mean displace-

\footnotetext{
${ }^{5}$ This will provide fewer estimates than what is shown in Fig. 8c, where a binned value was computed regardless of the number of observations.

${ }^{6}$ There are slightly fewer drifters and trajectories than in Fig. 13 because sufficient independent observations are not always available to define a mean and eddy components.
}

ments in along and across $f / h$ directions due to the mean flow (Fig. 14c).

Finally, unlike the results from a mean-eddy decomposition of float data by LaCasce (2000), here the mean flow makes a significant contribution to the dispersion. The mean flow may induce dispersion in regions with strong horizontal shear (LaCasce 2000). Dispersion by the mean flow is larger than dispersion by eddy processes in the along- $f / h$ direction. This reflects the large horizontal shear that develops because of topographical forcing of the mean circulation. However, eddy processes are the dominant mechanism allowing dispersion across contours of $f / h$ (Fig. 14e). Note that the eddyinduced dispersion grows roughly linearly in time, while the mean-induced dispersion grows more rapidly (dispersion of a unidirectional shear flow grows quadratically with time; Taylor 1953).

\section{Discussion and conclusions}

\section{a. Key regions}

Data obtained from the ADELIE drifters suggest that the western edge of the South Scotia Ridge and the area around Clarence Island are crucial choke points in the surface circulation. The former is a region 

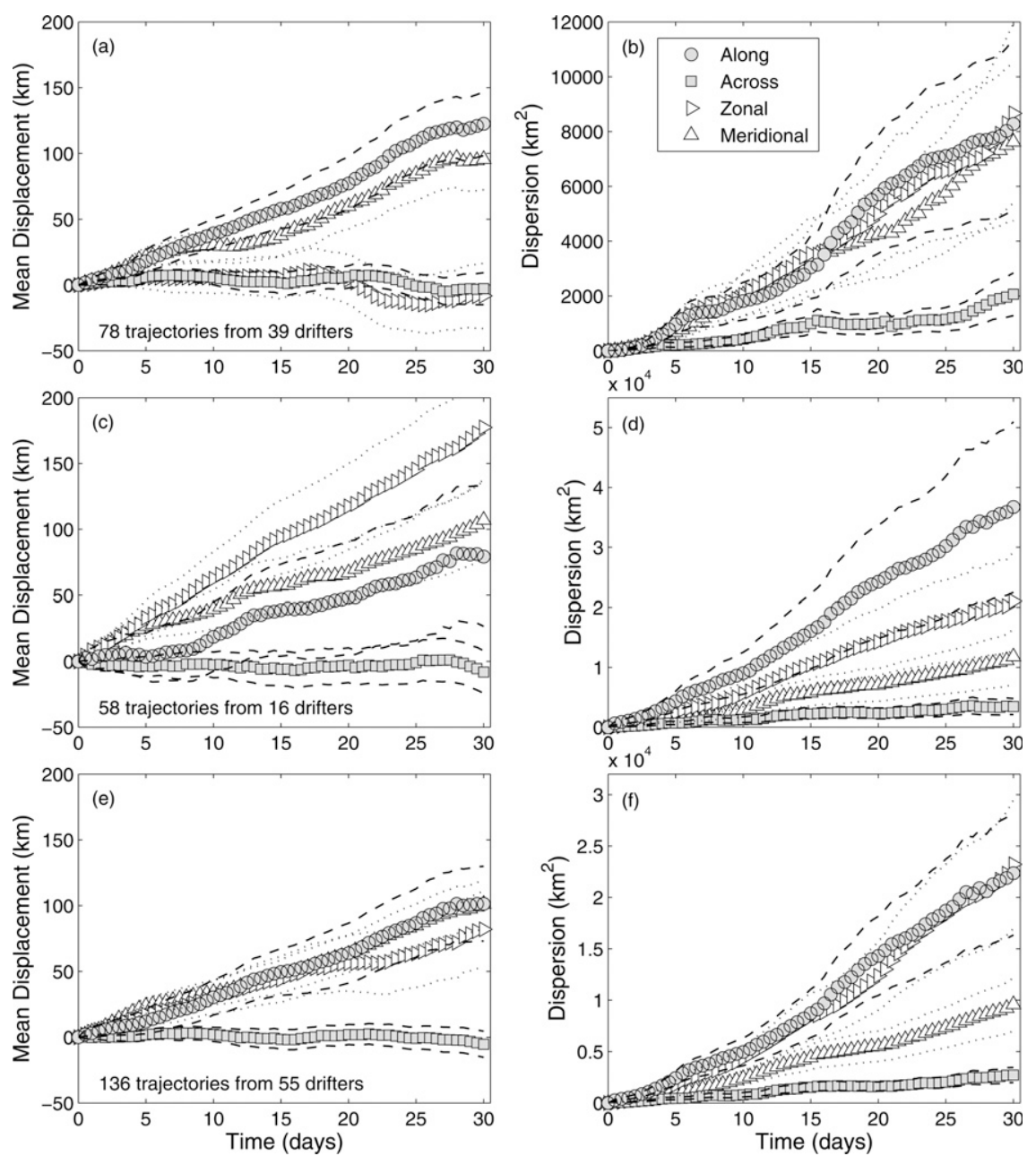

FIG. 13. Zonal, meridional, along-f/h, and across- $f / h$ mean displacement for the (a) ADELIE surface drifters, (c) historical surface drifters, and (e) combined surface drifter dataset. (b), (d), (f) Dispersion for the same three datasets is also shown. The dashed lines show the $95 \%$ confidence intervals for the along- and across- $f / h$ quantities while the dotted lines show the $95 \%$ confidence intervals for the zonal and meridional quantities. The number of drifters and the number of trajectories (of at least 15-day length) used in the calculations are given for each dataset.

of divergence with the ASF bifurcating upon reaching a topographical rise. An open question is whether pathways exist to carry tracers from the Weddell Sea and Bransfield Strait into current systems on the western side of the Antarctic Peninsula. A path of this nature would allow true circumnavigation of the continent and may be a mechanism for supporting a circumpolar coastal wave observed by Beckmann and Timmermann (2001) in their numerical simulations. This would also provide a mechanism to connect Antarctic krill populations either side of the Antarctic Peninsula and potentially on a circumpolar scale. Unfortunately, there are insufficient trajectories from this study to prove or disprove the link between current systems.
Around Clarence Island, the flow converges from regions with diverse properties including the Weddell Sea, Bransfield Strait, and the ACC. Thus, biological or chemical properties of the water in this region may display a high degree of temporal variability, and observations, which have been limited to hydrographic sections, may be unrepresentative of the region's mean properties.

Steering by topography generates regions of strong horizontal shear in the mean flow, especially along the northern and western boundaries of the large standing eddy over the South Scotia Ridge (Fig. 9). Regions of strong shear are typically associated with high variability; barotropic instability and eddy formation may also 

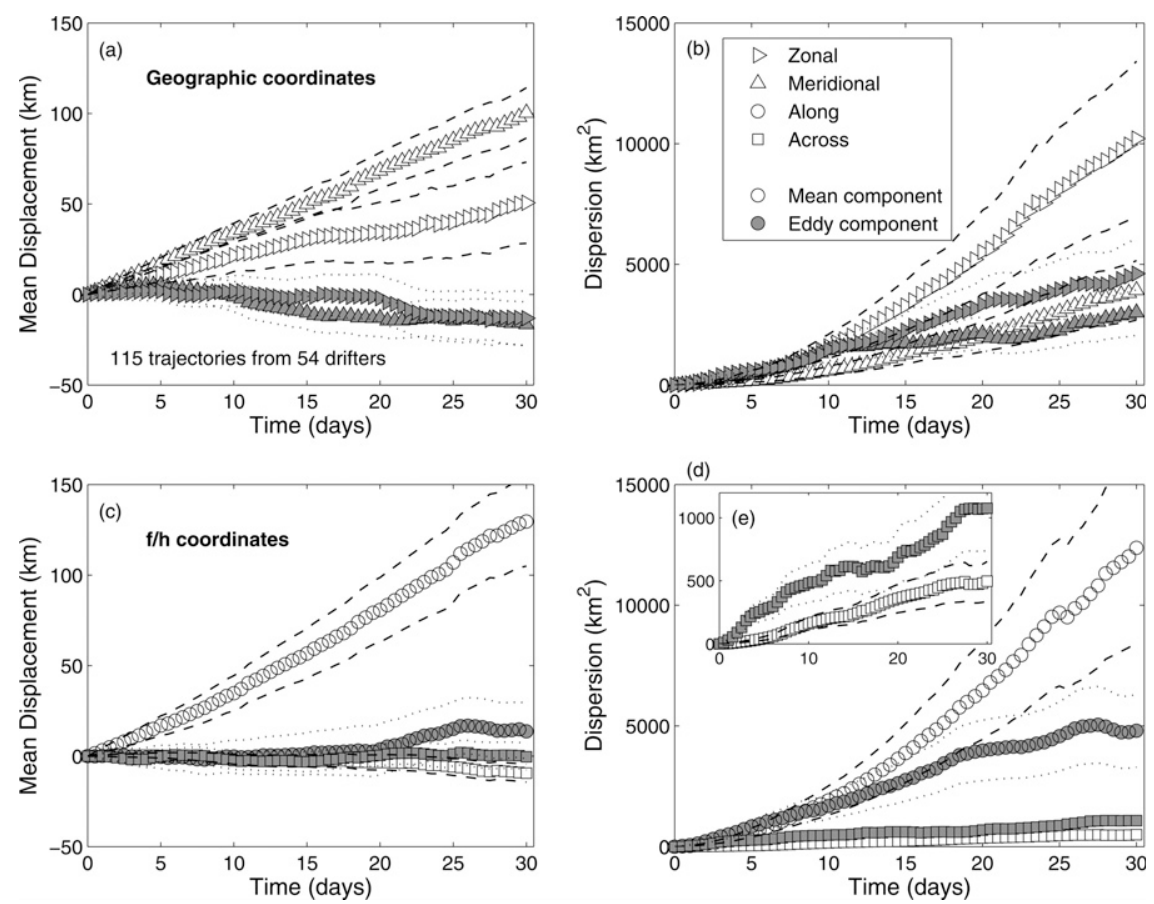

FIG. 14. Zonal and meridional (a) mean displacement and (b) dispersion calculated from mean (open symbols) and eddy (shaded symbols) components of the velocity observations. (c), (d) The same statistics are shown for along- and across-f/h directions. (e) The mean and eddy dispersions in the across- $f / h$ directionare expanded. Dashed lines are $95 \%$ confidence intervals for mean components of the flow, while dotted lines are the $95 \%$ confidence intervals for the eddy components.

occur. The large-standing eddy could be maintained, in part, by an instability process that continually extracts energy from the strong shears generated by the ASF and the western boundary current exiting Bransfield Strait. Although topography is almost certainly responsible for localizing the standing eddy, the mechanism that leads to the persistence of this feature is unclear from the surface drifter data. Biologically, the standing eddy is an interesting feature. The eddy may trap plankton within its core for long periods of time, which would influence the residence time of the organisms in this region. Heywood and Priddle (1987) discuss the retention of phytoplankton in an anticyclonic eddy located farther west in Bransfield Strait near $57^{\circ} \mathrm{W}$, but this feature is unrelated to the standing eddy described above.

The Southern Ocean's primary productivity is believed to be iron limited (Boyd et al. 2000). Of course, data obtained from the surface drifters only give information on surface velocities, providing an indication of transport paths in the area. This is not enough to prove that these paths transport iron into the ACC and enhance primary productivity. However, a recent survey of chlorophyll concentrations in the Weddell Scotia Confluence, sponsored by the Commission for the Con- servation of Antarctic Marine Living Resources (CCAMLR) (Watkins et al. 2004), suggests that the transport paths described here are correlated with regions of high primary productivity. In Fig. 3 of HolmHansen et al. (2004a) concentrations of Chlorophyll-a (Chl- $a$ ) in surface waters from 137 hydrographic stations are grouped into areas of low, medium, and high concentrations. The stations found at the eastern edge of Bransfield Strait and near Elephant Island have high concentrations adjacent to medium to low concentrations over Powell Basin and the South Orkney Plateau. This picture is also confirmed in satellite maps of monthly averaged Chl- $a$ during the CCAMLR study (December 1999-February 2000; Fig. 2 of HolmHansen et al. 2004b). Again, high Chl- $a$ concentrations are found over the South Scotia Ridge and hugging the eastern side of Clarence and Elephant Islands, while a region of low Chl- $a$ concentrations coincides with waters found between the eastern edge of the South Scotia Ridge and the eastern edge of the South Orkney Plateau as well as waters over the Hesperides Trough. These chlorophyll distributions indicate that the pathways described by the drifters are a likely source of limiting nutrients. 


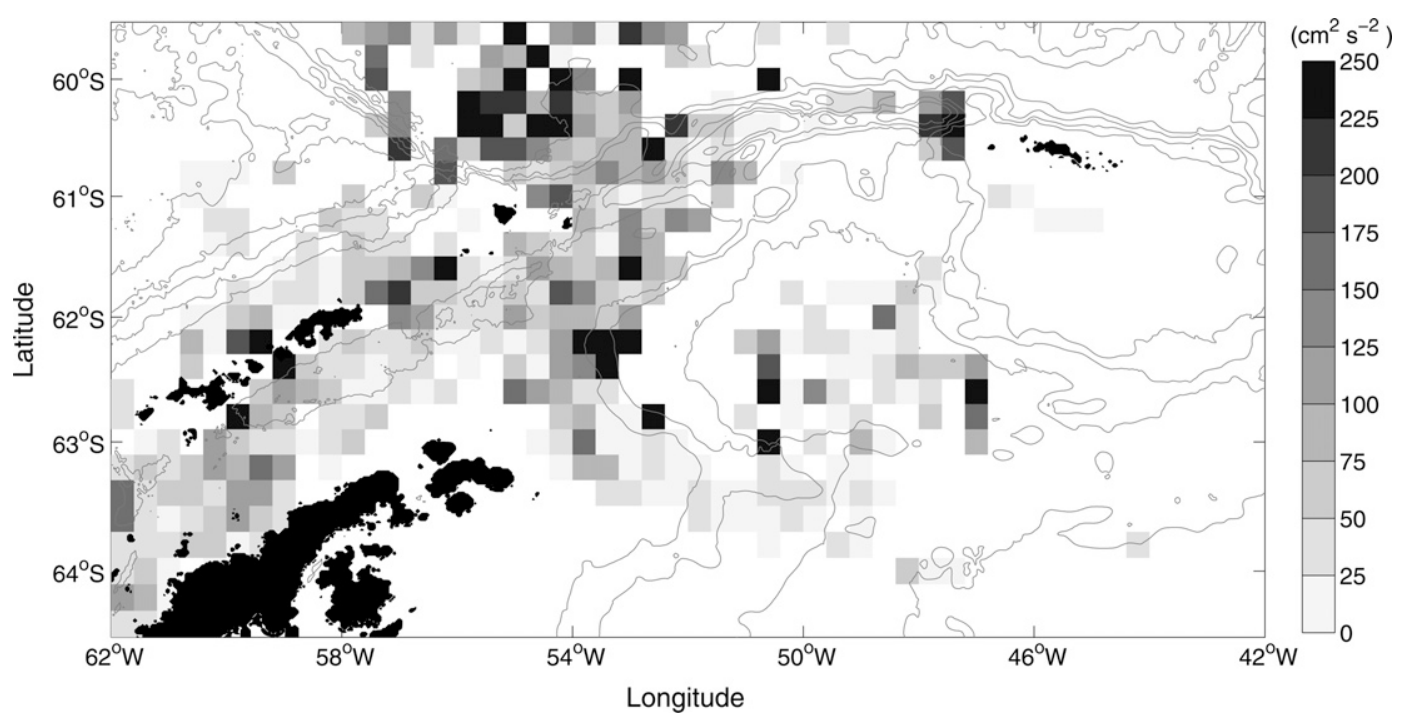

FIG. 15. Ratio of across- $f / h$ velocity variance to along- $f / h$ velocity variance multiplied by the EKE for normalization. The contours indicate bottom topography with contours every $1000 \mathrm{~m}$ between 1000- and 4000-m depth.

Assuming, then, that the transport paths described here are potential mechanisms for the export of iron, it is of interest to determine where iron-rich waters originating over the continental shelf are able to cross contours of $f / h$ to reach deeper waters. Figure 15 shows the ratio of the across- $f / h$ velocity variance to the along- $f / h$ velocity variance for bins where there are at least five independent estimates. The ratio is then multiplied by the eddy kinetic energy (as shown in Fig. 11b) for normalization, because the ratio can be abnormally large in bins where there is little eddy activity. Tracers are more likely to cross contours of $f / h$ where this quantity is large. Although large across- $f / h$ variance does not necessarily imply mean transport across-f/h contours, we expect cross-slope exchange to be large here because eddy processes dominate the cross-slope dispersion (Fig. 14). Also, regions in Fig. 15 that have large values largely correspond to areas where the across-f/h component of the mean circulation is significant (not shown). Neglecting the large values found in the Scotia Sea, the important regions of cross-slope exchange are likely found along the southern boundary of the South Scotia Ridge and to the northeast of Elephant and Clarence Islands.

Observations (Watkins et al. 1999) and modeling studies (Hofmann et al. 1998; Murphy et al. 2004) have linked the populations of Antarctic krill at the Antarctic Peninsula and the northern Weddell Sea to those around the island of South Georgia in the northeastern Scotia Sea. While we are unable to verify whether krill may be transported between these two regions purely from the drifter data, we have identified what are likely to be the key transport pathways between the coastal region near the Antarctic Peninsula and the Scotia Sea.

\section{b. Summary}

The surface circulation of the northwestern Weddell Sea has been studied using data from a set of 40 surface drifters deployed across the continental shelf and slope to the east of the tip of the Antarctic Peninsula. Combining these data with historical drifter data in the region, primarily within Bransfield Strait, we have identified new circulation features that update the schematic provided by Heywood et al. (2004) of the Antarctic Coastal Current and the Antarctic Slope Front (Fig. 3). These new features have a significant influence on the export of nutrient-rich shelf waters into the Antarctic Circumpolar Current. The drifter-derived circulation may also serve as a starting point for understanding how deep water escapes the Weddell Sea. This is possible because the circulation of the western Weddell Sea is largely barotropic and, more importantly, the deep outflow peaks in the same locations as the frontal currents found at the surface and in the interior (Fahrbach et al. 2001, TH08). Our major conclusions follow:

1) While the Coastal Current and the ASF appear as separate currents east of Joinville Island where the continental shelf is broad, these two features merge at the mouth of Bransfield Strait and dominate the circulation. Most drifters deployed shoreward of the 2500-m isobath become entrained in the ASF. Upon reaching the western edge of the South Scotia Ridge, trajectories describe one of three possible fates: (i) they turn west and flow into the southern 
portion of Bransfield Strait. The drifters may be returned to the South Scotia Ridge within the Strait's strong western boundary current. (ii) They become entrained in a large standing eddy centered at $62^{\circ} \mathrm{S}$ and $54^{\circ} \mathrm{W}$. This eddy has not, to our knowledge, been previously reported but is a persistent feature in the historical drifter data. (iii) They turn east and follow a complicated, topographically forced path allowing eventual export into the ACC.

2) The export of water masses from the western Weddell Sea may follow a number of complicated routes due to the bifurcation of the ASF at the western edge of the South Scotia Ridge, however, both ADELIE and historical surface drifters escape into the Antarctic Circumpolar Current from a relatively small geographical region (Fig. 7). Furthermore, while these export routes are well described by the mean circulation shown in Fig. 8, the path an individual drifter ultimately follows likely depends crucially on smaller-scale motions such as eddies, inertial oscillations, Ekman drift, and tidal forcing. The importance of these forcings, especially in regions highlighted in section 5a, requires further study.

3) The surface drifter trajectories are steered by contours of $f / h$ to a remarkable degree, considering they are drogued at $15-\mathrm{m}$ depth. The largest contribution to the dispersion of the drifters is due to regions of large shear in the mean flow; however, eddy processes are primarily responsible for dispersion across contours of $f / h$. The western edge of the South Scotia Ridge and the region between the Hesperides Trough and Clarence Island have been identified as potentially important regions for cross-slope exchange (Fig. 15). We emphasize that the tendency to follow contours of $f / h$ does not preclude two drifters starting in similar locations from describing very different trajectories. The different residence times within the Weddell Sea associated with different trajectories may have implications for Antarctic krill transport to South Georgia Island and for natural fertilization of the area by iron from the Antarctic Peninsula.

Acknowledgments. We are grateful to all who contributed to the success of the ADELIE research cruise, especially the officers and crew of the RRS James Clark Ross. We are grateful for support from Peter Niiler and the Global Drifter Program in augmenting our drifter array and supplying position fixes. Mayra Pazos was extremely helpful in providing near-real-time data on the drifter trajectories during the research cruise. Deb Shoosmith assisted in processing the shipboard ADCP data, and Kevin Manning provided the AMPS wind data. Comments from two anonymous reviewers helped clarify some important aspects of this study. The cruise was supported by the U.K. Natural Environment Research Council (NERC) through the Antarctic Funding Initiative, AFI6/25. AHHR was supported by a Marie Curie Early Stage Training Fellowship. ATC's participation was funded in part by the Royal Society's International Joint Projects Scheme. AT is an SNI (Mexico) grant holder and his participation was funded in part by the Royal Society's International Joint Projects Scheme, CICESE's Oceanology Division, and Unidad La Paz.

\section{APPENDIX}

\section{Calculating Displacement and Dispersion along and across $f / h$}

The drifter data were divided into 30-day segments to increase the sample number and the statistical certainty. Segments shorter than 30 days were only included if the trajectory lasted at least 15 days. This period is significantly longer than the Lagrangian time scale after which drift along $f / h$ is expected to occur (LaCasce 2000). No distinction is made for deployment date or for deployment location because of the limited size of the dataset. However, we examine the ADELIE and historical drifters separately (Fig. 13), which is roughly a geographical distinction between deployment east of and north of the Peninsula, respectively. Drifter trajectories that extend into the Antarctic Circumpolar Current are not included in this analysis.

The method of calculating along- and across- $f / h$ displacements involves projecting velocities onto axes parallel and perpendicular to contours of $f / h$ using local bathymetric gradient vectors. The bathymetry is taken from Smith and Sandwell (1997) and smoothed spectrally following LaCasce (2000) (Fig. A1a). The topography is Fourier transformed, then multiplied by an exponential filter to remove small scales:

$$
h=\sum_{k} \sum_{l} \hat{h}(k, l) \exp \left[-\alpha\left(k^{2}+l^{2}\right)^{1 / 2}-i k x-i l y\right],
$$

where $\hat{h}$ is the transformed topography and $\alpha$ is a smoothing factor taken to be $12.5 \mathrm{~km}$. We have also considered cases with $\alpha=6$ and $\alpha=25 \mathrm{~km}$, and this does not qualitatively influence the results described in section $4 \mathrm{~b}$. Filtering is intended to mimic the effects of stratification, although LaCasce and Speer (1999), using idealized quasigeostrophic simulations, showed that small topographic scales are irrelevant even in barotropic flows.

Following LaCasce (2000) we initially analyze the drifter tracks without a mean and eddy contribution 

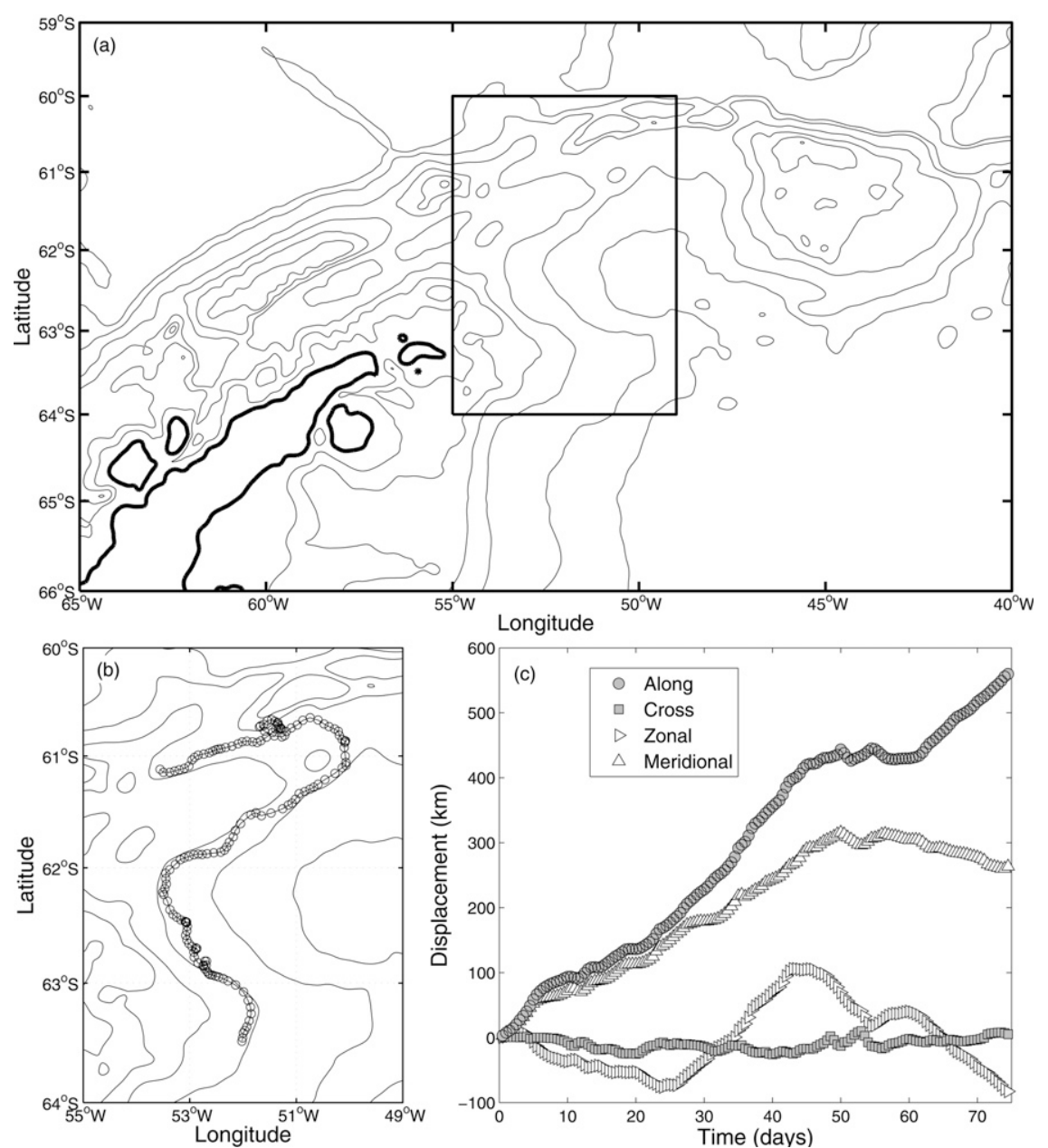

FIG. A1. (a) Smooth $f / h$ contours for the ADELIE study region. The contours values for $f / h$ are $(4,5,10,20,30,50) \times 10^{-8}(\mathrm{~m} \mathrm{~s})^{-1}$; land is indicated by the bold curve. The $f / h$ field is smoothed following (3), where the smoothing factor $\alpha$ is taken to be $12.5 \mathrm{~km}$. (b) Expanded view of the boxed region with the trajectory of drifter 71212 superimposed. The drifter trajectory has been filtered to remove tidal and inertial motions. (c) The displacement of drifter 71212 in zonal and meridional direction and also projected into along- and across- $f / h$ direction as described in the appendix.

and rather consider the drifter tracks as transport measurements. Displacements are calculated from twicedaily positions subsampled from the filtered, 6-hourly drifter tracks (see section 2) to determine zonal and meridional velocities. Along- and across- $f / h$ velocities are obtained by taking the cross and dot products, respectively, of the velocity vector with the local gradient vector for $f / h$. Positive across- $f / h$ velocities are defined as "uphill," while positive along-f/h velocities have the shallower topography to the left.

The mean displacement $M(t)$ is defined by

$$
M(t)=\frac{\sum_{i}\left[d_{i}(t)-d_{i}(0)\right]}{N} \pm z\left[\frac{D(t)}{N-1}\right]^{1 / 2},
$$

and the dispersion $D(t)$ is given by

$$
\begin{aligned}
D(t)= & \frac{\sum_{i}\left[d_{i}(t)-d_{i}(0)-M(t)\right]^{2}}{N-1} \\
& \times\left[1 \pm z\left(\frac{2}{N-1}\right)^{1 / 2}\right],
\end{aligned}
$$

where $d$ is displacement, $N$ is the number of measurements, and $z=1.96$ at the $95 \%$ confidence level if normal distribution is assumed (LaCasce and Speer 1999; LaCasce 2000). As noted by LaCasce (2000), displacements along and across $f / h$ do not conserve distance because $f / h$ is curvilinear. Figure A1b shows the 
trajectory from drifter 71212 overlaid on the f/h contours in the boxed region of Fig. A1a. The zonal and meridional along- and across- $f / h$ mean displacements for this single trajectory are shown in Fig. A1c.

\section{REFERENCES}

Atkinson, A., M. J. Whitehouse, J. Priddle, G. C. Cripps, P. Ward, and M. A. Brandon, 2001: South Georgia, Antarctica: A productive, cold water, pelagic ecosystem. Mar. Ecol. Prog. Ser., 216, 279-308.

Bauer, S. A., A. Griffa, M. Swenson, A. Mariano, and K. Owens, 1998: Eddy-mean flow decomposition and eddy diffusivity estimates in the tropical Pacific Ocean. 1. Methodology. $J$. Geophys. Res., 103, 30 855-30 871.

Beckmann, A., and R. Timmermann, 2001: Circumpolar influences on the Weddell Sea: Indication of an Antarctic circumpolar coastal wave. J. Climate, 14, 3785-3792.

Boyd, P. W., and Coauthors, 2000: A mesoscale phytoplankton bloom in the polar Southern Ocean stimulated by iron fertilization. Nature, 407, 695-702.

Chelton, D. B., R. A. deSzoeke, M. G. Schlax, K. El Naggar, and N. Siwertz, 1998: Geographical variability of the firstbaroclinic Rossby radius of deformation. J. Phys. Oceanogr., 28, 433-460.

Davis, R. E., 1991: Observing the general circulation with floats. Deep-Sea Res., 38 (Suppl.), S531-S571.

_ 1998: Preliminary results from directly measuring mid-depth circulation in the Tropical and South Pacific. J. Geophys. Res., 103, 24 619-24 639.

Fahrbach, E., G. Rohardt, and G. Krause, 1992: The Antarctic coastal current in the southeastern Weddell Sea. Polar Biol., 12, 171-182.

,$- \ldots$, M. Schroder, and V. Strass, 1994: Transport and structure of the Weddell Gyre. Ann. Geophys., 12, 840-855.

- S. Harms, G. Rohardt, M. Schroder, and R. A. Woodgate, 2001: Flow of bottom water in the northwestern Weddell Sea J. Geophys. Res., 106, 2761-2778.

Falco, P., A. Griffa, P.-M. Poulain, and E. Zambianchi, 2000: Transport properties in the Adriatic Sea as deduced from drifter data. J. Phys. Oceanogr., 30, 2055-2071.

Falkowski, P. G., R. T. Barber, and V. Smetacek, 1998: Biogeochemical controls and feedbacks on ocean primary production. Science, 281, 200-206.

Fitzwater, S. E., K. S. Johnson, R. M. Gordon, K. H. Coale, and W. O. Smith, 2000: Trace metal concentrations in the Ross Sea and their relationship with nutrients and phytoplankton growth. Deep-Sea Res. II, 47, 3159-3179.

Gill, A. E., 1973: Circulation and bottom water production in the Weddell Sea. Deep-Sea Res., 20, 111-140.

Hansen, D. V., and P.-M. Poulain, 1996: Quality control and interpolations of WOCE-TOGA drifter data. J. Atmos. Oceanic Technol., 13, 900-909.

Heywood, K. J., R. A. Locarnini, R. D. Frew, P. F. Dennis, and B. A. King, 1998: Transport and water masses of the Antarctic Slope Front system in the eastern Weddell Sea. Ocean, Ice, and Atmosphere: Interactions at the Antarctic Continental Margin, S. S. Jacobs and R. F. Weiss, Eds., Antarctic Research Series, Vol. 75, Amer. Geophys. Union, 203-214.

_ A. C. Naveira Garabato, D. P. Stevens, and R. D. Muench, 2004: On the fate of the Antarctic Slope Front and the origin of the Weddell Front. J. Geophys. Res., 109, C06021, doi:10.1029/2003JC002053.

Heywood, R. B., and J. Priddle, 1987: Retention of phytoplankton by an eddy. Cont. Shelf Res., 7, 937-955.

Hofmann, E. E., J. M. Klinck, R. A. Locarnini, B. A. Fach, and E. J. Murphy, 1998: Krill transport in the Scotia Sea and environs. Antarct. Sci., 10, 406-415.

Holloway, G., 1992: Representing topographic stress for largescale ocean models. J. Phys. Oceanogr., 22, 1033-1046.

Holm-Hansen, O., and Coauthors, 2004a: Factors influencing the distribution, biomass, and productivity of phytoplankton in the Scotia Sea and adjoining waters. Deep-Sea Res. II, 51, $1333-1350$

- and Coauthors, 2004b: Temporal and spatial distribution of chlorophyll- $a$ in surface waters of the Scotia Sea as determined by both shipboard measurements and satellite data. Deep-Sea Res. II, 51, 1323-1331.

Jacobs, S. S., 1986: The Antarctic Slope Front. Antarct. J. U.S., 21, 123-124.

1991: On the nature of the Antarctic Slope Front. Mar. Chem., 35, 9-24.

Korb, R. E., M. J. Whitehouse, and P. Ward, 2004: SeaWIFS in the southern ocean: Spatial and temporal variability in phytoplankton biomass around South Georgia. Deep-Sea Res. II, 51, 99-116.

Kottmeier, C., J. Olf, W. Frieden, and R. Rainer, 1992: Wind forcing and ice motion in the Weddell Sea. J. Geophys. Res., 97, 20 373-20 383.

LaCasce, J. H., 2000: Floats and f/h. J. Mar. Res., 58, 61-95.

— , and K. Speer, 1999: Lagrangian statistics in unforced barotropic flows. J. Mar. Res., 57, 245-275.

Martin, J. H., R. M. Gordon, and S. E. Fitzwater, 1990: Iron in Antarctic waters. Nature, 345, 156-158.

McWilliams, J. C., and J. M. Restrepo, 1999: The wave-driven ocean circulation. J. Phys. Oceanogr., 29, 2523-2540.

Muench, R. D., and A. L. Gordon, 1995: Circulation and transport of water along the western Weddell Sea margin. J. Geophys. Res., 100, 18 503-18 515.

Murphy, E. J., S. E. Thorpe, J. L. Watkins, and R. Hewitt, 2004: Modeling the transport pathways in the Scotia Sea: Spatial and environmental connections generating the seasonal distribution of krill. Deep-Sea Res. II, 51, 1435-1456.

Niiler, P. P., A. S. Sybrandy, K. Bi, P.-M. Poulain, and D. Bitterman, 1995: Measurements of the water-following capability of holey-sock and TRISTAR drifters. Deep-Sea Res. I, 42, 1951-1964.

- N. A. Maximenko, and J. C. McWilliams, 2003: Dynamically balanced absolute sea level of the global ocean derived from near-surface velocity observations. Geophys. Res. Lett., 30, 2164, doi:10.1029/2003GL018628.

Olson, D. B., V. H. Kourafalou, W. E. Johns, G. Samuels, and M. Veneziani, 2007: Aegean surface circulation from a satellitetracked drifter array. J. Phys. Oceanogr., 37, 1898-1917.

Orsi, A. H., W. D. Nowlin, and T. Whitworth, 1993: On the circulation and stratification of the Weddell Gyre. Deep-Sea Res., 40, 169-203.

_, G. C. Johnson, and J. L. Bullister, 1999: Circulation, mixing and production of Antarctic Bottom Water. Prog. Oceanogr., 43, 55-109.

Padman, L., H. A. Ricker, R. Coleman, S. Howard, and S. Erofeeva, 2002: A new tidal model from the Antarctic ice shelves and seas. Ann. Glaciol., 34, 247-254. 
Patterson, S. L., and H. A. Sievers, 1980: The Weddell-Scotia Confluence. J. Phys. Oceanogr., 10, 1584-1610.

Pauly, T., S. Nicol, I. Higginbottom, G. Hosie, and J. Kitchener, 2000: Distribution and abundance of Antarctic krill (Euphausia superba) off East Antarctica $\left(80-150^{\circ} \mathrm{E}\right)$ during the Austral summer of 1995/1996. Deep-Sea Res. II, 47, 2465-2488.

Richardson, P. L., 1982: Gulf Stream paths measured with freedrifting buoys. J. Phys. Oceanogr., 11, 999-1010.

Rio, M.-H., and F. Hernandez, 2003: High-frequency response of wind-driven currents measured by drifting buoys and altimetry over the world ocean. J. Geophys. Res., 108, 3283, doi:10.1029/2002JC001655.

Robertson, R., 2005: Baroclinic and barotropic tides in the Weddell Sea. Antarct. Sci., 17, 461-474.

Schodlok, M. P., H. H. Hellmer, G. Rohardt, and E. Fahrbach, 2006: Weddell Sea iceberg drift: Five years of observations. $J$. Geophys. Res., 111, C06018, doi:10.1029/2004JC002661.

Smith, W. H. F., and D. T. Sandwell, 1997: Global sea floor topography from satellite altimetry and ship depth soundings. Science, 277, 1956-1962.

Taylor, G. I., 1921: Diffusion by continuous movements. Proc. London Math. Soc., 20, 196-212.

_ 1953: Dispersion of soluble matter in solvent flowing slowly through a tube. Proc. London Math. Soc., A219, 186-203.

Thompson, A. F., 2007: ADELIE cruise report: RRS James Clark Ross cruise 158, 9 February-20 February 2007. UEA Cruise Rep. Series 9, University of East Anglia, Norwich, United Kingdom, 86 pp.
, and K. J. Heywood, 2008: Frontal structure and transport in the northwestern Weddell Sea. Deep-Sea Res. I, 55, 12291251.

Vallis, G. K., and M. E. Maltrud, 1993: Generation of mean flows and jets on a beta plane and over topography. J. Phys. Oceanogr., 23, 1346-1362.

Wadhams, P., C. Sear, D. Crane, M. Rowe, S. Morrison, and D. Limbert, 1989: Basin-scale ice motion and deformation in the Weddell Sea during winter. Ann. Glaciol., 12, 178-186.

Watkins, J. L., A. W. A. Murray, and H. I. Daly, 1999: Variation in the distribution of Antarctic krill Euphausia superba around South Georgia. Mar. Ecol. Prog. Ser., 188, 149-160.

—, R. Hewitt, M. Naganobu, and V. Sushin, 2004: The CCAMLR 2000 survey: A multinational, multi-ship biological oceanography survey of the Atlantic sector of the Southern Ocean. Deep-Sea Res. II, 51, 1205-1214.

Whitworth, T., A. H. Orsi, S.-J. Kim, W. D. Nowlin, and R. A. Locarnini, 1998: Water masses and mixing near the Antarctic Slope Front. Ocean, Ice, and Atmosphere: Interactions at the Antarctic Continental Margin, S. S. Jacobs and R. F. Weiss, Eds., Antarctic Research Series, Vol. 75, Amer. Geophys. Union, 1-27.

Zhou, M., P. P. Niiler, and J.-H. Hu, 2002: Surface currents in the Bransfield and Gerlache Straits, Antarctica. Deep-Sea Res. I, 49, 267-280.

,,-- Y. Zhu, and R. D. Dorland, 2006: The western boundary current in the Bransfield Strait, Antarctica. Deep-Sea Res. I, 53, 1244-1252. 